\title{
SEARCH TECHNIQUES IN ELECTRONIC DICTIONARIES: A CLASSIFICATION FOR TRANSLATORS
}

\author{
Verónica Pastor: TecnoLeTTra Team, Departamento de Traducción y Comunicación, \\ Universitat Jaume I (vpastor@trad.uji.es) \\ Amparo Alcina: TecnoLeTTra Team, Departamento de Traducción y Comunicación, \\ Universitat Jaume I (alcina@trad.uji.es)
}

\begin{abstract}
Translators, and language professionals in general, have long claimed that dictionaries are deficient, especially regarding access and updating of content. Some authors have also noted that these deficiencies are compounded by the fact that language professionals do not receive (proper) training in dictionary use, and therefore do not fully benefit from them. Electronic dictionaries include new search capabilities, not found in traditional dictionaries, that could meet users' needs. However, the diversity of search options in electronic dictionaries makes their classification difficult, and consequently hinders training in their use. Systematization of search techniques in electronic dictionaries would favor the teaching and learning process, and could also facilitate the task of lexicographers and terminographers in the creation of new and more standardized electronic dictionaries. In this paper we classify search techniques in electronic dictionaries by focusing on three elements that are common to every search and that, taken together, encompass all the search possibilities we have observed in electronic dictionaries.
\end{abstract}

\section{Introduction}

Terminology is a key factor in translators' work. The development of specialized fields has grown hand in hand with advancements in science and technology. Translators have to meet the challenge imposed by high levels of text specialization, as well as the thematic diversity of the texts to be translated. These market demands explain why translators are calling for resources to satisfy their terminological needs quickly and effectively (Alcina 2009).

The use of electronic dictionaries has many advantages over the traditional paper dictionary. However, access to the lexicon and terminology of a dictionary presents certain difficulties, partly due to the lack of user knowledge (even among language experts such as translators) about how a dictionary can be queried to access this kind of information, and partly due to the diversity of ways a dictionary can be consulted (in different areas of the dictionary, with different operators, in widely varied interfaces) which vary from one dictionary to another.

Many studies can be found in the literature on dictionary use by translators (Meyer 1988, Roberts 1990, Atkins and Varantola 1998, Mackintosh 1998, Sánchez 2004a), and also by native speakers of a language, and language learners (Tomaszczyk 1979, Béjoint 1981, Bogaards 1988, Tono 1989, Hulstjin and Atkins 1998, Hartmann 1999, McCreary and Dolezal 1999). Most of these and other authors conclude that users come across difficulties in their dictionary consultations, generally due to two main causes: the dictionary does not facilitate access to information (dictionaries present deficiencies and are not user-friendly), and users are unaware of how to use dictionaries to access the information they contain (Béjoint 1989: 280, Cowie 1999: 188, Hartmann 
1999: 40, Nesi and Haill 2002: 285, Fernández-Pampillón and Matesanz 2003: 150, Sánchez 2004a: 482).

These difficulties imply that translators do not take full advantage of the search possibilities offered by electronic dictionaries, and frequently turn to other resources, such as the Internet and corpora, to look for the terminology they need.

Against this background, training programs should perhaps be incorporated to teach translation studies students how to use dictionaries, as suggested by Corpas et al. (2001: 255), "el diseño curricular de la licenciatura debería incluir una parte dedicada exclusivamente a los diccionarios, ubicándola dentro de las distintas fuentes de documentación a disposición del traductor e intérprete" [degree curricula should include a section devoted exclusively to dictionaries, as part of the documentation sources available to the translator and interpreter], and also by Roberts (1997): "translators have not learned to use their dictionaries efficiently. Dictionary use is not an integral part of school and university curricula. And even schools of translation and interpretation rarely have courses specifically designed to teach dictionary use". It is clear that the success of a query depends on the intelligent use of search tools (Varantola 1998: 180), and that translators must know the limitations and capacities of their dictionaries and how to use them efficiently (Fraser 1999: 32).

In addition, dictionaries do not always take advantage of the full potential offered by electronic formats. Electronic dictionaries are frequently mere copies of paper dictionaries; they are texts where the same information appears in different font styles. However, these dictionaries do not offer the search possibilities of an advanced database system.

Despite these reflections in the literature, we have found no studies that establish a "universal" classification or arrangement of the search techniques that can be used in a dictionary, in other words, one that is valid for training in electronic dictionary use in general, and that can be adapted to any specific dictionary. By this, we refer to a classification that can specify and highlight all the query options a dictionary offers. This classification may serve as a guide to design search types when creating a new electronic dictionary, either from scratch or based on a paper dictionary.

The present research, within the framework of the ONTODIC Project, investigates how to incorporate new search techniques, such as onomasiological searches (Alcina 2009), in electronic dictionaries. This has led us to analyze the search techniques that are currently available in electronic dictionaries (in this paper), as well as in electronic corpora (Pastor and Alcina 2009), and the Internet (Pastor and Alcina, 2010).

In the present paper, we first analyze the reflections offered by some authors on the features of electronic dictionaries, mainly in contrast to paper dictionaries (section 2 ). This is followed (section 3) by an analysis of fifteen advanced electronic dictionaries, from which we compiled all the search possibilities offered by electronic dictionaries, including the most common and well known, as well as the most innovative. Following this analysis we present our empirical study, summarized in Table 1. Section 4 then describes our search techniques classification, based on the authors' reflections and the dictionary analysis. In this classification we focus on three main elements that cover all the search possibilities. We term these three elements the query, the resource, and the result. The combination of these three elements and their subtypes allow us to structure all the search techniques that can be used in dictionaries. Finally, we conclude by highlighting the practical uses and contributions our classification provides. 


\section{Electronic dictionaries and search possibilities}

The development of new technologies and the Internet have progressively modified the concept of the dictionary. Many paper dictionaries have been converted to electronic formats, such as CD-ROM, while others are available online.

Electronic dictionaries can be classified in various types according to different criteria. Some authors have attempted to devise typologies of electronic dictionaries (Ide 1993, Sharpe 1995, Nesi 1998, 1999, 2000b). One example of an electronic dictionary typology is that by Lehr (1996: 315), which focuses on technical and meta(lexicographic) evaluation. Based on technical evaluation, this author distinguishes between online or offline dictionaries. Offline dictionaries comprise pocket electronic dictionaries (PEDs) and PC dictionaries. PC dictionaries include dictionaries in CDROM, floppy disk and other formats. Based on meta(lexicographic) evaluation, this typology distinguishes between electronic dictionaries based on their paper versions, and newly developed electronic dictionaries, as well as electronic dictionaries with both print and innovative appearances.

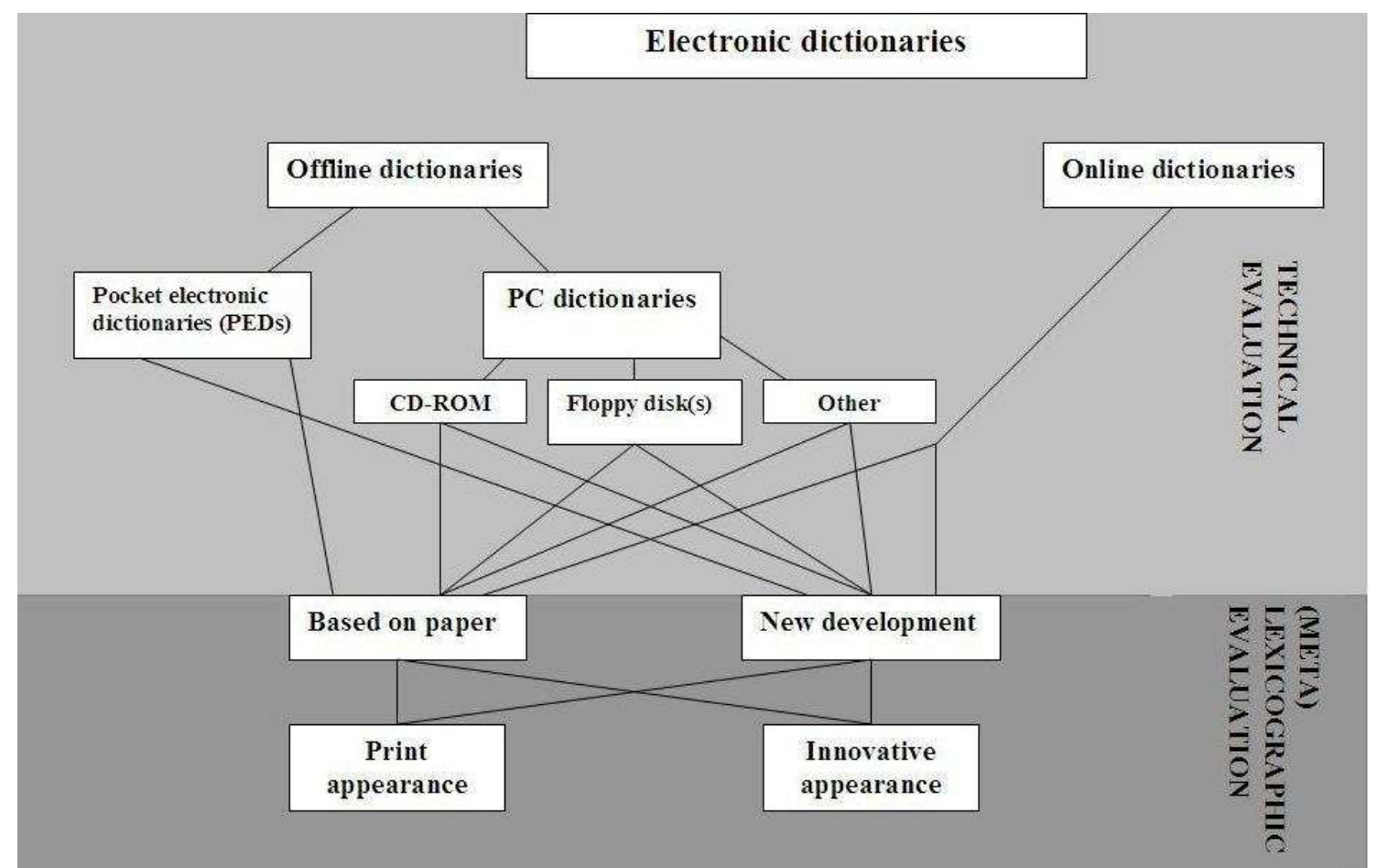

Figure 1. Classification of electronic dictionaries by Lehr (1996: 315, translated in de Schryver 2003: 148).

In this classification, the author distinguishes between newly developed electronic dictionaries (new development) and electronic versions of paper dictionaries (based on paper) (Gross 1997, Jacquet-Pfau 2002: 90). Nesi (2000a: 140) states that fully electronic dictionaries are more effective than electronic dictionaries adapted from paper versions: "electronic dictionaries would be most effective if they were designed from scratch with computer capabilities and computer search mechanisms in mind". Electronic dictionaries can be easily updated (Kay 1984: 461, Carr 1997: 214, Harley 2000) and allow a quicker, more precise, and exhaustive search, in which a variety of search criteria can be combined (Jacquet-Pfau 2002: 99, de Schryver 2003: 157). According to Sharpe (1995: 48), electronic adaptations of paper dictionaries incorporate the same type of searches as paper dictionaries, and their search possibilities are therefore less flexible. 
Forget (1999) affirms that electronic dictionaries differ from paper dictionaries in factors such as use, presentation, search capabilities, technical aspects, and nature of contents (multimedia elements). With regard to the first of these factors, for example, this author points to the use of hypertext in electronic dictionaries, and a higher flexibility in searches as compared to paper dictionaries. Forget also states that every electronic dictionary has a different interface, and as a result the user must devote more time to learning how to use each one of the electronic dictionaries available.

The presentation of electronic dictionaries often involves the use of different colors to highlight information, as well as more intuitive interfaces. Electronic dictionaries are reported to incorporate different search types, and although electronic searches are always quicker than manual searches, much time can also be wasted on searching in an electronic dictionary without obtaining a satisfactory result.

Finally, technical aspects mentioned include the interactivity of electronic dictionaries, which allow the user to add to a dictionary entry a comment that may be useful in future searches, such as a usage note, a context, a translation used for a specific client, etc. In addition, users can copy terms directly from the dictionary without having to type them, electronic dictionaries take up less space than paper dictionaries, and do not deteriorate with time.

Of all the differences between electronic and paper dictionaries already mentioned in this section, the main difference stated by many authors, and that we want to emphasize here, lies in the way the user accesses the information in a dictionary (Nesi 1998, de Schryver 2003: 147). Search possibilities in paper dictionaries are limited: the search is restricted to the arrangement of contents by the lexicographer, which is always alphabetical (Sallas 2001) and, therefore, is limited to the search for an exact word (Santana et al. 1996: 70). In contrast, searches in electronic dictionaries are quicker and more flexible because they incorporate more advanced search techniques (Sánchez 2004b: 181, Kaalep and Mikk 2008).

Some authors have reflected on the types of searches that have already been implemented in electronic dictionaries, or that would be desirable to incorporate, such as de Schryver's (2003) paper "Lexicographer's Dreams in the Electronic-Dictionary Age". In this publication the author calls for dictionary designs that would allow more complex searches, and reviews all the authors that have dealt with the advances or desires in the development of electronic dictionaries to date. Knowles (1990: 1656) suggests the use of hyperlinks; Abate (1985) mentions the use of images and graphics, as well as the use of natural language in searches; Poirier (1989) refers to the search in the whole text of the dictionary with Boolean operators; Sobkowiak (1999) mentions access to corpora concordances as a dictionary option; Nesi (2000a) suggests simultaneous searches in different dictionaries; Corris et al. (2000) refer to functions of the dictionary that suggest similar spellings to the search words; Geeraerts (2000) considers search functions by inverse indexes, anagrams, and phonetic similarity.

Dodd (1989: 89) also refers to the search capabilities of electronic dictionaries and anticipates the possibility of searching for a word from its phonetics, spelling similarities, etymology, thematic area, semantic relations with other words (synonymy, antonymy, hyponymy), words in the definition, part of speech, etc.

Many electronic dictionaries allow searches in the entire dictionary content, or in some of its sections, and not only in the entries (Roberts and Langlois 2001: 712), for example in dictionary definitions or contexts. In addition, hyperlinks in electronic dictionaries link words that are related to other words (Nesi 1999: 61, Gómez GonzálezJover 2005: 161, Church 2008). Hamon and Nazarenko (2001: 187) identify different types of hyperlinks: in the entry index, in the keywords, and in relations of synonymy 
and hypernymy between entries and subentries. The inclusion of images in dictionaries is also a very useful complement to linguistic information (Faber et al. 2007, Montero and Faber 2008: 151). Another option of electronic dictionaries is the possibility to access the most recent entries the user consulted, similar to the search history in web search engines (Forget 1999, Rizo and Valera 2000: 369).

Fernández-Pampillón and Matesanz (2003) distinguish the following types of searches: search in an entry, search in a list of entries (alphabetical or inverse), assisted search, multiple search, search with related words (use of the dictionary as a thesaurus), search in anagrams, and search using abbreviations and marks.

Sánchez (2004b: 193-194) includes a range of searches: a search in the entries, similar to an alphabetical search in paper dictionaries; an assisted search in which the dictionary suggests words when the user has misspelled the search word; an advanced search, which allows the user to search in the dictionary content (definitions, examples, etc.); a search with wildcards, patterns defined by the user, and filters, which allows the user to combine search words with operators, and to search for orthographical variants with wildcards; a search for related words, which accesses words that are semantically related to other words; a search with anagrams, which retrieves words that result from changing the order of the letters the user introduces in the dictionary; a search with abbreviations and marks, which retrieves all the forms corresponding to abbreviations and marks used in the dictionary entries; and finally a refined search, which retrieves words by introducing their pronunciation or etymology.

Moreover, it is worth noting that a term's meaning is determined not only by the concept it refers to, but also by the context in which it is used (Kussmaul 1995: 89, Corpas et al. 2001: 253, Robinson 2003: 113); hence, the importance given by translators and other language professionals to the search for terms within their context of use. Currently, dictionaries, even electronic ones, do not have a wide enough contextual field to solve all user needs.

Bowker (1998: 648) states that dictionaries lack contexts compared to the valuable information offered by electronic corpora. Bowker performed a study with translation students in which half the students translated a text using dictionaries only, and the other half used electronic corpora and WordSmith tools. She found that the translations produced by the students with access to corpora were of a higher quality than those from the students that had only used dictionaries. These context-related deficiencies of dictionaries are one of the reasons some authors (Montero and Faber 2008: 162) give to explain why translators have gradually moved from searching in dictionaries to other resources, such as the Internet and corpora, which offer users wider contexts and facilitate access to these contexts by means of various search techniques that dictionaries have not yet incorporated.

Because contexts are so relevant to translators and other language professionals, some studies call for the incorporation of corpora within the search systems of electronic dictionaries. In this way, corpora are not simply a source for creating dictionaries, nor a dictionary substitute (Colominas 2004: 362), but rather a complement to or accessory of the dictionary. In this vein, works like that of Castagnoli (2008) are of particular interest; this author created a database in which the contextual field is eliminated from the entries, and terms in the entries are linked to a reference corpus where the user can consult the concordances of a term.

In this section we have outlined some of the reflections many authors have made on electronic dictionaries, with particular attention to how they differ from paper dictionaries. Specifically, the literature highlights aspects such as interactivity, variety, 
and flexibility in the searches. However, we have found no exhaustive studies on dictionary search possibilities, or on how these search possibilities could be organized.

We therefore detected the need to develop a classification of search techniques in electronic dictionaries, through the analysis of a set of electronic dictionaries and the search possibilities they offer.

\section{Analysis of search techniques in electronic dictionaries}

In this study we analyzed fifteen electronic dictionaries. The criterion used to select the dictionaries was that they should incorporate innovative search techniques as well as the traditional alphabetical search. In addition, we analyzed both online and offline dictionaries in order to examine the advantages and disadvantages of both formats. Online dictionaries are more accessible than the CD-ROM format, and most online dictionaries are free. Moreover, online dictionaries can be consulted on any computer (with Internet access), and the dictionary does not have to be installed in the computer in order to use it. However, offline dictionaries generally provide more search techniques than online dictionaries, and are more stable and durable compared to online dictionaries. The virtual nature of online dictionaries means that their URL location may change at any time, or they may even disappear all together.

In this section we first describe dictionaries available on CD-ROM, in Spanish, such as the Diccionario de uso del español by María Moliner, and the Diccionario de la lengua española by the Real Academia Española, and in English, such as the Oxford English Dictionary and the Collins English Dictionary. We then analyze online dictionaries and databases, in alphabetical order, such as Cercaterm, the DiCoInfo dictionary, EOHS Term, FrameNet, Lexical FreeNet, Macmillan English Dictionary, the Merriam-Webster monolingual English dictionary, thesaurus, and visual dictionary, the OneLook Reverse Dictionary, the Ultralingua dictionary, WordNet, the WordReference dictionary and the Wordsmyth dictionary.

We briefly describe the search options that these dictionaries offer, focusing on the specificities of each one. This is intended to give an overall picture of the diverse query options that can be found in electronic dictionaries before we proceed, in the following section, to the systematization of search techniques.

The Diccionario de uso del español (DUE) is a monolingual general Spanish dictionary in CD-ROM format developed by the Spanish lexicographer María Moliner. It allows four types of searches:

-in the list of entries: the dictionary shows an alphabetical list of all the dictionary entries starting with the word or sequence of characters introduced by the user;

-in the entries: the dictionary retrieves a list of words that are alphabetically similar to that introduced by the user when the searched word is not found in the dictionary. A peculiarity of this option is that it retrieves the base form ${ }^{1}$ of an inflected form (the inflected form of a verb, or a plural noun, etc.). This option is particularly useful in searches made in inflectional languages, such as romance languages;

-in the definitions: the dictionary generates a list of words whose definitions contain all the words introduced in the dictionary with the operator ' $\&$ ' or some of the words introduced with the operator ' $l$ '. Words whose definitions do not contain the words introduced with the operator '!', or that contain an "exact expression" introduced in quotation marks can also be searched;

-anagrams: the dictionary retrieves words that result from a combination of all the letters introduced. 
The Diccionario de la lengua española (DRAE) is a monolingual general Spanish dictionary developed by the Real Academia de la Lengua Española. It is available both online and offline. The online version only allows an exact search or a search for words that are alphabetically or orthographically similar to the introduced word. The CD-ROM version performs different types of searches. It allows specific queries such as the inverse alphabetic search, which orders the list of entries alphabetically from the last letter introduced to the first, instead of from the first letter to the last. The search for complex forms retrieves all the entries whose headword includes the word introduced by the user. Words can also be retrieved that include in their definition or in other section of an entry any word the user introduces. Another function offered is the search for anagrams with the letters the user introduces, or by randomly adding three more letters to the anagrams, or discarding three letters. This dictionary also includes a list of abbreviations and tags that can be useful to find entries containing a particular abbreviation or information. The following wildcards can also be used: ? (replaces any character), * (replaces zero or a sequence of characters) ++ (replaces one or more characters), [...] (searches any of the letters introduced in the square brackets), [!...] (searches any letters except those introduced after the exclamation mark in square brackets), @ (replaces a vowel), \# (replaces a consonant).

The DRAE also offers a search tree option. Search trees are hierarchical structures with different types of information (etymological, grammatical, geographic, register, or semantic information). For instance, the etymological information branch contains Latin, Greek and Romance. If the user selects any of these branches, the dictionary retrieves a list of entries tagged with that information.

The Oxford English Dictionary (OED), in CD-ROM, is a monolingual English dictionary developed by Oxford University Press. The dictionary headwords (words, phrases, variant forms, phonetics) can be searched and it allows the use of date and partof-speech filters. It can also search in all the text of the dictionary, in the definitions, in the etymology, or quotation fields. This dictionary allows the use of the wildcards * (replaces zero or more characters) and ? (replaces only one character).

The Collins English Dictionary (CED), in CD-ROM, is a monolingual English dictionary developed by HarperCollins Publishers. This dictionary has a dictionary search option and a thesaurus option (thesaurus entries include semantically related words). It also searches for anagrams; operators (AND, OR, NOT, and parenthesis) and wildcards $(*, ?)$ can be used to search in the definitions. It has a history option to access the user's most recent queries.

Cercaterm is a multilingual online dictionary developed by the Terminology Center TERMCAT. It contains terminology in Catalan, Spanish, English, and French. The main difference from other dictionaries lies in its classification of terms by thematic area. The search interface allows the user to restrict the search to a specific thematic area.

The DiCoInfo is a French ${ }^{2}$ online dictionary of Computer Science based on the Explanatory Combinatorial Lexicology (ECL) developed by the Observatoire de linguistique Sens-Texte (OLST) Group at the University of Montreal. According to the ECL, the lexical unit has three components: a meaning, a form and a set of combinatorial properties (Mel'čuk et al. 1995: 16). Each meaning of a term corresponds to a lexical unit, and therefore has a different entry in the DiCoInfo; in other words, each meaning of a word is dealt with in separate entries followed by a number $(1,2$, etc.) that specifies each meaning (L'Homme 2008). For example, the word address has three entries in the DiCoInfo, address ${ }_{1}$, address ${ }_{2}$ and address $s_{3}$. In this way it differs from other dictionaries where all the meanings of a polysemous word are included in the same 
entry. The DiCoInfo entries also include examples of the word in context, and it can be used to search for collocates. Each entry contains a field of lexical relationships (liens lexicaux) where paradigmatic and syntagmatic relations (that is, collocates) are located (L'Homme 2008). The search option lien lexical retrieves entries that contain the words the user introduces in the field of lexical relationships. For example, verbal collocates of the term fichier 'file' can be accessed, such as modifier un fichier or éditer un fichier.

The EOHS Term online database (http://eohsterm.org) (Castagnoli 2008) was developed by the Linguaggi e Attività Produttive project at the Advanced School of Modern Languages for Interpreters and Translators (SSLMIT), University of Bologna in Forlì. The main feature of this database is that the context field is deleted from the entries, and the words are linked to a reference corpus where the user can access the contexts.

FrameNet is another online dictionary, developed by the Berkeley FrameNet Project, that allows the user to search for the combinatory possibilities in each meaning of a word (each meaning also corresponds to a different lexical unit) (Ruppenhofer et al. 2006). This resource is based on semantic frames (Fillmore 1985, Fillmore and Atkins 1998, Fillmore et al. 2003). The database is divided in two parts: the frame database, and the lexical database. Each entry in FrameNet represents a lexical unit, a pairing of a lemma with a semantic frame (corresponding to one sense of a word). In each entry the user can see the Frame Elements that occur with a particular lexical unit and the syntactic patterns in which they occur. The entry also includes annotated examples from a corpus for every combinatory possibility. (Fillmore et al. 2002).

Lexical FreeNet is an English online lexical database or semantic network, developed by the Datamuse Corporation in collaboration with many research groups such as The WordNet 1.6 Group at Princeton University. It combines the semantic relations of WordNet with other semantic data and phonetic relations ${ }^{3}$. A particular feature of this dictionary is that it allows the user to restrict the search to a part of speech (noun, adjective, verb, and adverb), as well as to a type of relation (synonym, antonym, pronunciation, generalization, etc.).

The show related search option allows the user to look for words related to the one they have introduced. The connection option retrieves words that are simultaneously related to two words introduced by the user. With the rhyme coercion option the user also introduces two words; the retrieved words are related to both the words introduced, and in addition are phonetically similar. The spell check option retrieves words that are orthographically similar to the introduced word, for example, the word door retrieves door, dolor, donor, doors, etc. Finally, the substring option retrieves words that start, end, or contain the sequence of characters introduced by the user, for example, the word door retrieves doorbell, doorcase, doorframe, indoors, outdoorsy, etc.

The online version of the Macmillan English Dictionary is a monolingual English dictionary and thesaurus developed by Macmillan Publishers Limited. This dictionary allows an alphabetical search of words. The user must introduce an exact word to search in the alphabetical list of entries in the dictionary. However, certain features are also available to help the user find a word. The dictionary has an autocomplete feature, which means that while the user is introducing a word in the dictionary, a dropdown list appears with suggestions for terms that correspond to entries in the dictionary. For instance, if the user starts by writing uncon, the dictionary suggests searching for unconcealed, unconcern, unconcerned, unconcernedly, unconditional, etc. In addition, the dictionary retrieves a list of words that are alphabetically similar to that introduced by the user when the searched word is not 
found in the dictionary. The results in this dictionary are the entries that correspond to the user's search word. These entries include a variety of information, such as the definition of a word, which as well as appearing in written format, also includes audio files encapsulating the meaning of certain words, as pictures do in other dictionaries. For example, it provides audio representations of words such as whisper, which are not imageable, but which can be explained through a sound. Entries also include grammatical information, pronunciation, examples of use (with links from each word in the example to the dictionary entries that correspond to that word), and typical phrases containing the search word. Finally, entries access a thesaurus, where the user can find synonyms and related words.

The online Merriam-Webster's dictionaries, developed by Merriam-Webster, include several types of dictionaries. The monolingual English dictionary allows the user to search for exact words, but also includes hyperlinks between related words. The thesaurus offers synonyms, antonyms, and related words. The Merriam-Webster's dictionaries also include a visual dictionary that retrieves images associated with a word introduced by the user, and that can also be accessed from a thematic index. These images show the user details such as the names of different parts of an object. For example, in the image of a flower the petals are identified along with the name used to refer to them.

The OneLook Reverse Dictionary is an online monolingual English dictionary, developed by Doug Beeferman. This dictionary has its own entries and is also a metadictionary, meaning that it searches for the word in other dictionaries. It allows the user to search for a word by introducing words that define it. A specific feature of this dictionary is that words can be searched by introducing questions in natural language, such as what is a tropical fruit? The result of this search would be a list of names of tropical fruits (pineapple, mango, guava, papaya, sapodilla, etc). In addition, it retrieves words that start, end, or contain a sequence of characters the user introduces with a wildcard.

Ultralingua website, developed by Ultralingua Inc., includes online monolingual dictionaries and dictionaries of synonyms in English and French, as well as bilingual dictionaries of different language combinations: English, French, Spanish, Portuguese, German, Italian, Latin, and Esperanto. Like the other dictionaries described, it generates lists of words that start, end, or contain a sequence of characters that is introduced with a wildcard. Various wildcards can be used, such as the question mark '?' (replaces a single character), or the asterisk ' $*$ ' (replaces zero or more characters) and the plus symbol ' + ' (replaces one or more characters). This dictionary also retrieves the base form of a dictionary term that corresponds to the inflected form introduced by the user.

WordNet is a lexical database (Fellbaum 1998) or a semantic dictionary ${ }^{4}$ (Miller 1998a: 7) in English, developed at Princeton University, and available online. WordNet organizes the lexicon by semantic relations, mainly synonymy. Terms are grouped with their synonyms (sets of synonyms or synsets) (Miller 1998b: 23). Each group of synonyms is linked to other groups of synonyms by means of conceptual, semantic, and lexical relations. This dictionary allows the user to search for semantically related words (synonyms, hyponyms, hypernyms, etc.). This database has been used as a model to develop other dictionaries such as Eurowordnet, which is a multilingual database for several languages, including Spanish, German, French, Italian, Dutch, Czech and Estonian. The wordnets in this dictionary are based on the Princeton wordnet.

The WordReference website, developed by Michael Kellogg, allows the user to query a series of online monolingual and multilingual dictionaries. Multilingual dictionaries offer a wide variety of language combinations: Spanish, English, French, 
Portuguese, and Italian. WordReference also includes monolingual Spanish and English dictionaries, and a dictionary of synonyms in Spanish. The multilingual dictionaries allow the search for an exact word and provide equivalences. The monolingual English dictionary provides definitions of the introduced word, as well as links to other related words. The monolingual Spanish dictionary allows users to search for an exact word in the dictionary headwords; to search for entries whose definition contains all the words introduced by the operator ' + '; that are not contained in the definition the words introduced by the operator '-'; that contain exact combinations of words introduced in quotation marks "“"; and words that start, end, or contain a sequence of characters by combining them with an asterisk ' $*$ '.

An innovation not found in the other dictionaries is the WordReference forum, where dictionary users can participate by asking and answering questions. The dictionary has a further two options (in context and images) that link the dictionary to Google. The in context option links the dictionary to the Google web search, and the images option, to Google images. In both cases, the user enters a word which is automatically searched for in Google; the dictionary then opens a new window where the user can see the results of the search directly in Google.

Wordsmyth is an online monolingual English dictionary, developed by the Wordsmyth Organization. It allows four types of searches. As in many of the dictionaries described, the user can search for an exact word, with the exact option. The asterisk ' $*$ ' or the percentage sign ' $\%$ ' can be used to replace an unlimited sequence of characters, and the dot ' ' or the underscore or understrike '-' to replace a single character. The broad search retrieves definitions, synonyms, examples, and words related to the word introduced by the user. The spelled-like search retrieves words that are spelled in a similar way to the introduced word. The advanced search retrieves the dictionary entries that contain the words introduced by the user in the definitions, examples, synonyms, or related words.

This analysis is summarized in the comparative table in annex 1 , which presents all the search options described and the dictionaries in which each search option is available. The vertical axis of the table shows the search options, and the dictionaries analyzed appear on the horizontal axis. Comments are also added on some search options in each dictionary.

\section{Classification of search techniques in electronic dictionaries}

Our review of the search techniques reported in the literature and our analysis of the search techniques in electronic dictionaries reveal a wide variety of search possibilities. Not all the dictionaries incorporate the same search options. In addition, the same types of searches have different names, depending on the dictionary.

We therefore consider it necessary to systematize all the search techniques that have been incorporated in electronic dictionaries to date. The purpose of this paper is to present a proposal for the classification of search techniques in electronic dictionaries. Our search technique classification is divided into three elements that we have found to be present in every search: the query, the resource, and the result. By differentiating the query, the resource, and the result, we are able to reflect clearly and coherently all the search possibilities offered by each dictionary.

Search techniques are options that a user can apply to a resource to obtain a result. The user wants to obtain particular information (the meaning of a word, a usage context, etc.), and to obtain this information the user queries an electronic resource by introducing an expression, which we call the query. The electronic resource queried by 
the user can be a dictionary section, for example, a dictionary field where the user can find information. The specific element of the electronic resource queried by the user is called the resource. Finally, by introducing a query in a resource, the user obtains a result, the third element of our classification. Therefore, we distinguish three elements in a search technique: a query, a resource and a result. The query is the word or phrase introduced by the user in the interface of a resource. The resource is the resource or part of the resource in which the word or phrase is searched. The result is the element obtained when a query is searched in a resource.

In a dictionary, if we introduce the exact word house as a query to search in the list of dictionary entries (resource), the result we obtain is the dictionary entry for the word house with information about this word. In contrast, if the query we introduce is a combination of words, for example yellow fruit and we search in the definition field of a dictionary (resource), the result we obtain is a list of words whose definition field contains the words introduced in the query.

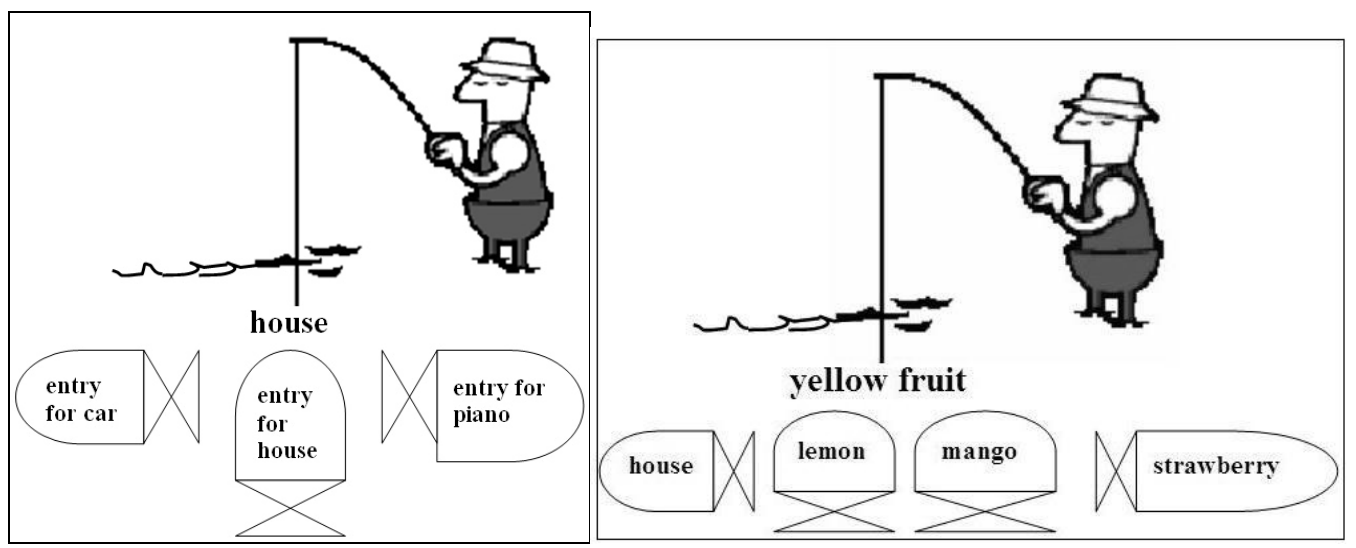

Figure 2. Representation of two search techniques in a dictionary.

Below, we explain in more detail the search techniques included in our classification, and provide examples of how these search techniques are applied in the electronic dictionaries we have analyzed.

\subsection{The first element: the query}

The query is the expression introduced by the user when searching in a dictionary. It is normally an exact word. In some cases, the user may introduce a partial word, for example, part of a word. In other dictionaries we can introduce an approximate word, an anagram, or a sequence of characters that may or may not form a word. Some dictionaries allow the user to introduce a combination of two or more words.

Together with the expression, the user can also introduce other information, in the form of filters, in order to restrict or specify the result they want to obtain. A filter limits the expression to a particular criterion, such as a part of speech or a thematic field. For instance, a filter for the word play could be the noun part of speech.

The types of queries we have discerned in electronic dictionaries fall into a range of search technique types and subtypes: 1) an exact word, 2) a partial word, 3) an approximate expression, (inflectional form, or spelling similarity), 4) an anagram, and 5) a combination of two or more words.

4.1.1 Search by exact word. The search by an exact word consists of introducing a complete word in the same form as it is included in the dictionary. This search can be 
used to obtain the dictionary entry containing information about the introduced word (a definition, an example, grammatical information, etc.). This option is offered by all dictionaries. For example, the user can search in the dictionary for the word house in the list of entries of the dictionary and find its definition, etymology, etc. The search of an exact word may be accent and case sensitive or not.

4.1.2 Search by partial word. A partial word is an incomplete word. The omitted part of the word can be the start, the middle or the end of the word. This omitted part of the word is replaced by a wildcard. The most frequent wildcards are the asterisk ' $*$ ', and the question mark '?'.

The question mark '?' normally replaces only one character. For example, analy? ed retrieves analyzed and analysed.

The asterisk (*) normally replaces one or more characters. For example, house $e^{*}$ retrieves housemaid, housewife, housebreaking, household, housekeeper, etc.

Of the analyzed dictionaries, these two wildcards can be used in the OneLook Reverse Dictionary, CED, OED, and the Diccionario de uso del español by María Moliner $(D U E)$. In some dictionaries other wildcards can be used. The Ultralingua dictionary uses the asterisk (to replace zero or more characters), the question mark, and also the plus sign ' + ' which replaces one or more characters. The Wordsmyth dictionary uses the asterisk ' $*$ ' or the percentage sign ' $\%$ ' to substitute any sequence of characters, and the dot '.' or the underscore or understrike '_' to replace one character. Finally, the Lexical FreeNet dictionary has an option called substring that retrieves words that start, end or contain the characters introduced, for example, the sequence reach retrieves the words reach, reachable, preach, unreachable, overreached, etc.

In addition, almost all the electronic dictionaries that we have analyzed include an auto-complete feature, which means that when the user starts introducing a word in the dictionary, a drop-down list appears suggesting entries included in the dictionary that start with the letters that the user is introducing. For example, in the Macmillan English Dictionary, if we start by introducing ima, the dictionary suggests words such as image, imagery, imaginable, imaginary, imagination, etc.

4.1.3 Search by approximate expression. An approximate expression is a word or sequence of characters that is similar to an exact word included in the dictionary. The approximate expression can be an inflected form of a word, or a word or sequence of characters that is pronounced or spelled similarly to other word. This search technique can be useful to obtain a list of words included in the dictionary that are similar to the word or sequence introduced by the user. We explain this search technique in more detail below.

4.1.3.1 Search by inflected form. An inflected form is a word with inflectional morphemes, for example a plural noun or a conjugated verb. When the user introduces an inflected form in a dictionary, the dictionary retrieves the base form of that word, which corresponds to the headword of a dictionary entry. For example, in the Ultralingua dictionary, if we introduce a conjugated verb, the dictionary retrieves the infinitive, or if we introduce a plural noun or adjective, it retrieves a singular noun or an adjective. Figure 3 illustrates the search for the conjugated verb played in the Ultralingua dictionary; the dictionary retrieves the entries that include the base form of this verb, the infinitive play. 


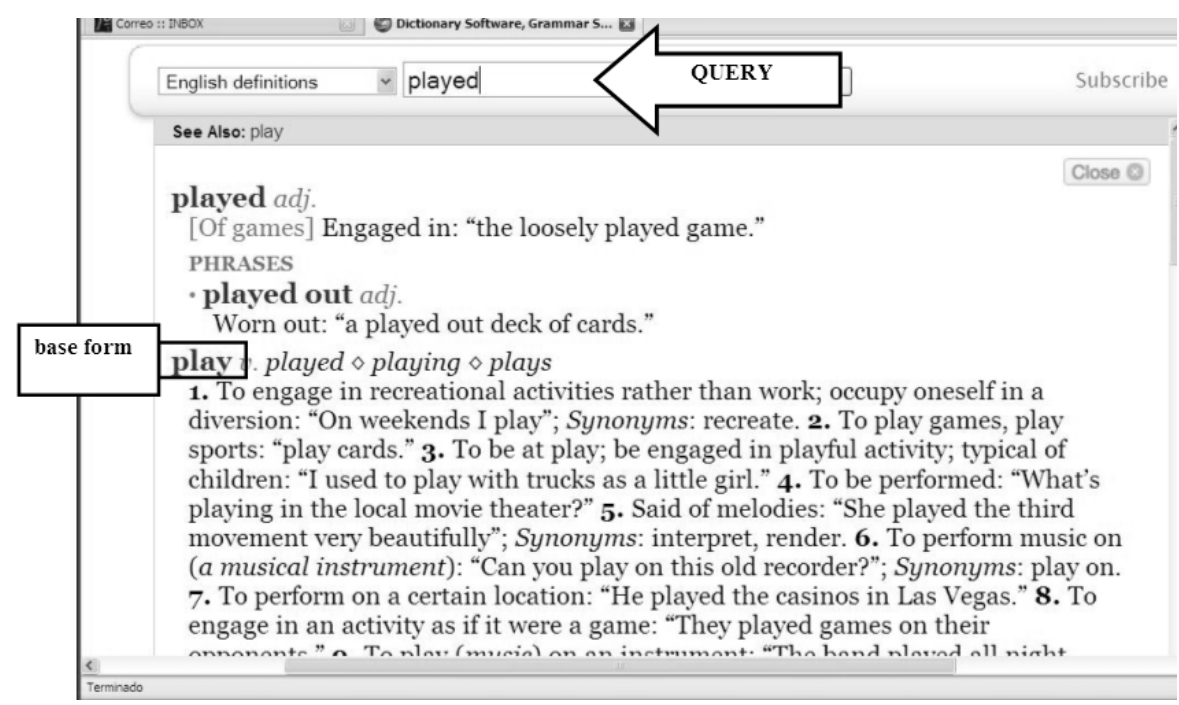

Figure 3. Search by inflected form in the Ultralingua dictionary.

4.1.3.2 Search by a similarly pronounced or spelled word. This search technique consists of introducing a sequence of characters that may or may not constitute a word and that are spelled or pronounced similarly to a word that is included in the dictionary. For example the búsqueda en las entradas option in the DUE searches for words spelled like the one the user introduces. As displayed in Figure 4, if we introduce the word perr, the dictionary retrieves words with similar spellings, such as peor 'worse', pero 'but', perro 'dog', etc.

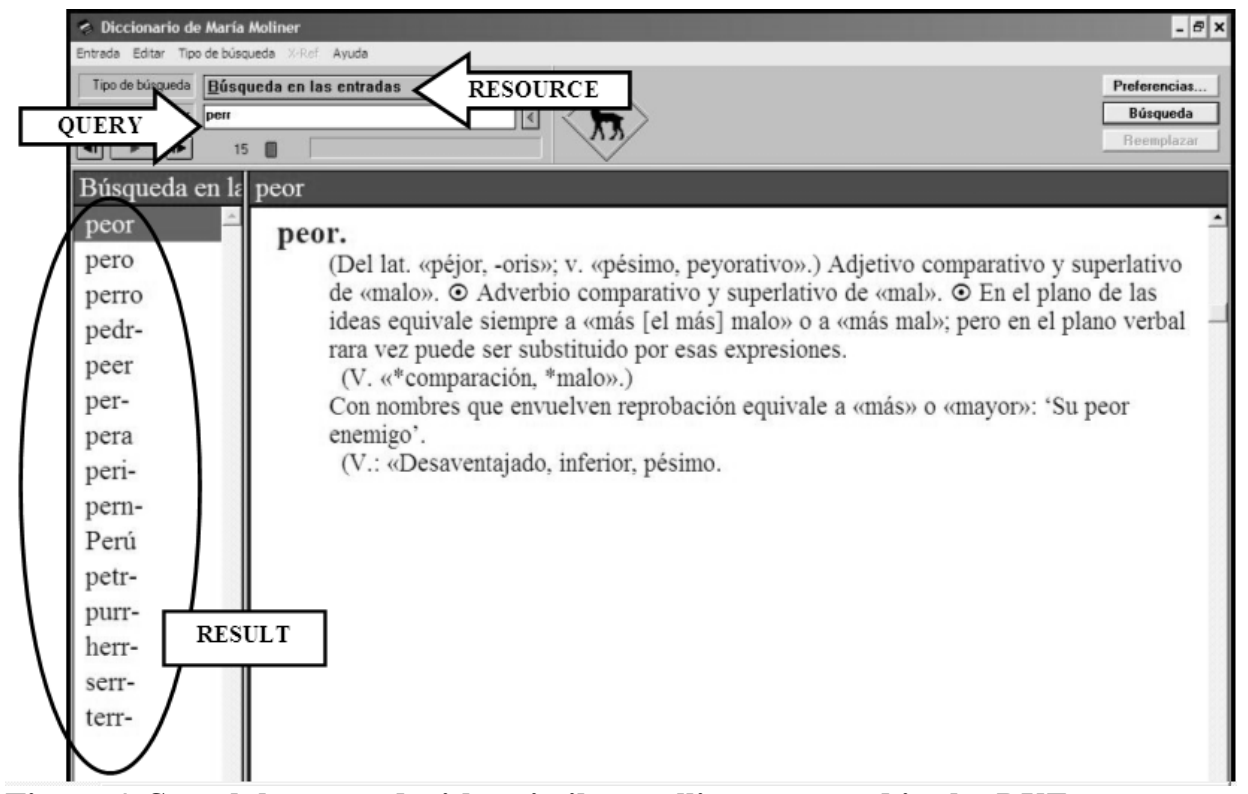

Figure 4. Search by a word with a similar spelling to a word in the DUE.

Wordsmyth includes the spelled-like option, which retrieves words that are spelled like the one the user introduces. For example, if we introduce the approximate expression setelment, the dictionary retrieves the words battlement, sediment, seducement, settlement, statement and supplement.

Lexical FreeNet has two options to look for approximate expressions. One option, called spell check, retrieves words with a similar spelling to the introduced word. For example, the introduction of the word broad retrieves broad, abroad, byroad, road, etc. Other options called sounds-like and rhyme retrieve words that are phonetically similar 
to the word introduced. For example, if we introduce the word congratulations, some of the results are: nations, stations, creations, crustaceans, conjugations, etc.

In addition to these specific search options provided by some dictionaries to search for a similarly pronounced or spelled word, almost all the electronic dictionaries that we have analyzed include a feature suggesting similarly spelled words that are included in the dictionary when the search word is not found. For instance, in the Macmillan English Dictionary, if we introduce wron, the dictionary does not display any result, but it suggests other similar words from the dictionary, such as wrong, wren, pron, iron, won, wrote, etc.

4.1.4 Search by anagram and crossword search. An anagram is a sequence of characters that may or may not constitute a word, whose transposition results in one or more complete words included in the dictionary. An anagram search can be useful to obtain a list of dictionary words that contain all the letters of the anagram, in the same or a different order. Some dictionaries can also randomly add or discard a number of letters specified by the user (crossword search). These search techniques are useful for finding a word if we know some or all of the letters it contains.

Anagram searches can be found in the $D U E, D R A E$, and the $C E D$. If we introduce the letters bowle in the $C E D$ and select the anagrams option, a list of words made up of those letters is retrieved: bowel, below and elbow. In addition, DRAE can perform crossword searches. For example, if we introduce the letters casa, and select the option of generating words by adding up to three more letters, we retrieve a long list of words including: asca 'teak', casa 'house', actas 'records', casal 'country house', caseta 'hut, stand or kennel', casuca 'shanty or hovel', casería 'country house', caserna 'barracks', etc.

4.1.5 Search by combination of two or more words. Search by a combination of two or more words consists of introducing two or more words in the dictionary at the same time. Our analysis revealed five ways of combining words in a query: 1) presence of all the words introduced, 2) presence of any of the words introduced, 3) presence of one word and absence of another, 4) presence of the exact sequence of words, 5) introduction of words in the form of a question in natural language. Dictionaries normally combine words using operators.

In the dictionaries analyzed, the search for two or more words can be made in content fields, for example, to obtain a list of dictionary words whose definition contains the words included in the query, or that are related to the query words.

4.1.5.1 Presence of all words. In this search technique all the words included in the query must be present in the resource. Below, we present some examples.

In the first example we combine the words agreement and lawsuit without operators in the OneLook Reverse Dictionary. The result we retrieve is a list of words, including: settle, accord, contract, champerty, etc. All the words retrieved by the dictionary are related to the query words. Figure 5 shows part of the entry for the word settle in the dictionary, where settle is given as a verb used in lawsuit contexts to designate the agreement reached by the parties. 


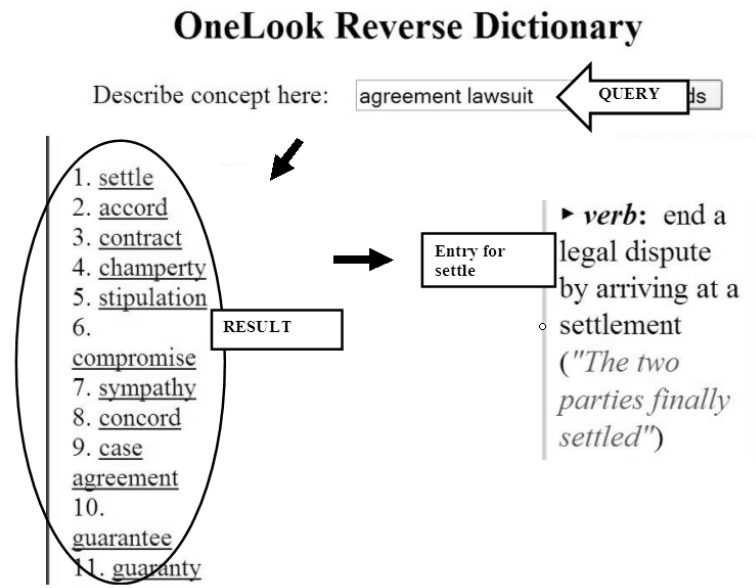

Figure 5. Presence of the words agreement and lawsuit in the OneLook Reverse Dictionary.

The operators used to indicate that all the words must be present can vary from one dictionary to another. The DUE uses the operator \& to combine two words, one at each side of the operator (word1 \& word2). In this case, the dictionary retrieves the entries that contain both query words in their content fields. Other dictionaries that allow the presence of all words are WordReference, CED, and Wordsmyth. WordReference uses the operator,$+ C E D$ the operator AND, and Wordsmyth requires the option all of the words.

The example in Figure 6 presents a search in WordReference with the operator + . We introduce the query +amarillo + fruto 'yellow and fruit'. The result is a list of words: albérchigo 'apricot', almeza 'hackberry fruit', amaranto 'amaranth', grosellero 'redcurrant bush', limón 'lemon', etc. The definitions of these words contain both query words. The entry for the word limón 'lemon' represented in Figure 6 includes the query words in the definition.
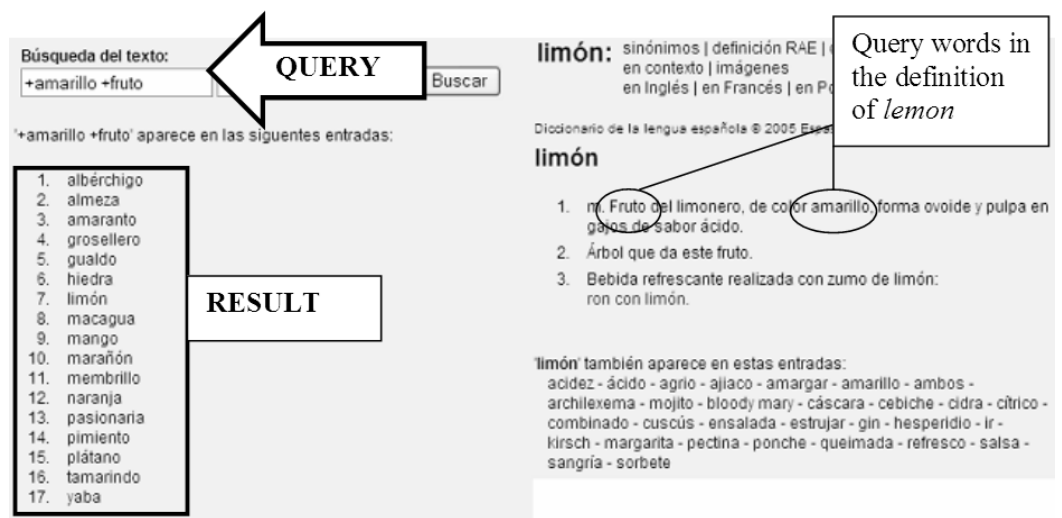

Figure 6. Presence of all words using operators in WordReference.

4.1.5.2 Presence of any of the words. The operators used to indicate that any of the query words can be present also vary from one dictionary to another. In the DUE, the operator $I$ is used in combination with two words, one at each side of the operator (word1 I word2). In this case, the dictionary retrieves entries that include only the first or the second word introduced with the operator, or both words at a time. In the CED, the operator OR is used. In the Wordsmyth dictionary, the any of the words option retrieves entries that include any of the words the user introduces.

Figure 7 shows an example of this search technique in the Wordsmyth dictionary. We introduce a four-word query, case, transport, carry and arrows, to search for in the 
dictionary definitions (any of the words and definition options). The dictionary retrieves a list of over 100 words whose definition includes any of the words introduced. In this list we find words such as quiver, which is defined as a case designed to hold and transport arrows, often strapped to the back or waist. This definition contains three of the four query words. The list also includes other words whose definition contains only one of the query words, for example, sentence. One of the definitions of sentence is $a$ formal judgment, including terms of punishment, such as that passed by a judge after trial of a case at law. The criterion used by the dictionary to list the words is alphabetical. The dictionary does not prioritize entries with a higher number of query words in their definition.

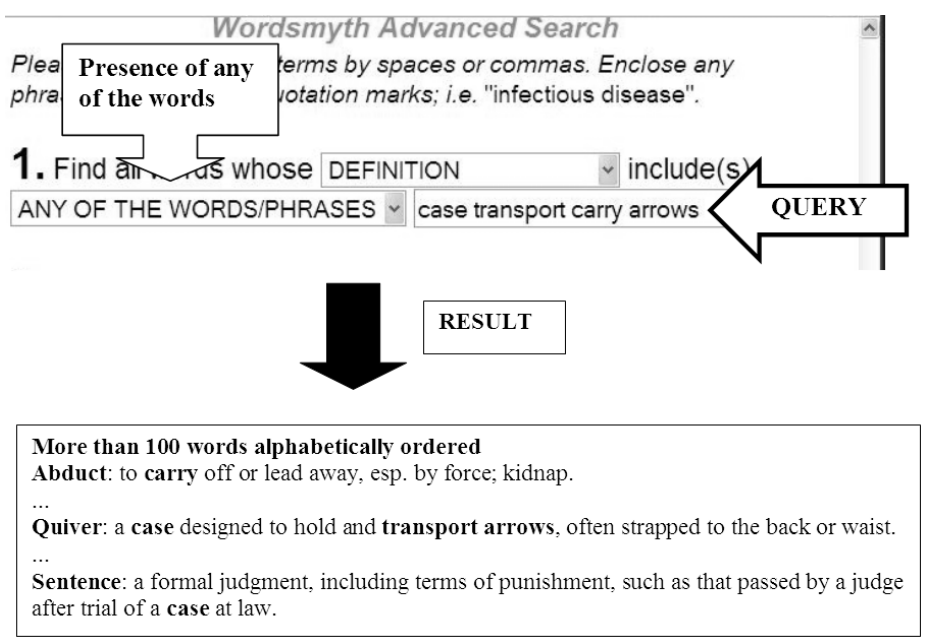

Figure 7. Presence of any of the words using operators in the Wordsmyth dictionary.

4.1.5.3 Presence of one word and absence of another word. In this search technique some of the words must be present in the content field of the dictionary and others must not be present. Of the dictionaries analyzed, only WordReference, CED, and DUE allow this search technique. DUE uses the operator !, which is combined with two words, one at each side of the operator (word1 ! word2). This option retrieves entries whose definitions include the first word, with the condition that the second word does not appear. The WordReference dictionary uses the operator -, which retrieves entries that do not contain the words preceded by that operator. The CED uses the operator NOT.

Figure 8 presents an example of this search in the $C E D$. We combine the words feline NOT domestic, to search in the definition fields. We retrieve entries whose definition contains the word feline but not domestic. The result is a list of words referring to felines: bobcat, caracal, cheetah, feline, jaguar, jaguarondi, leopard, lion, lynx, etc. The definitions of these words include the word feline, but not domestic. As we can see in the definition of leopard, the word feline is included, but domestic is not. In the search results the word cat does not appear because it is defined in the dictionary as domestic feline.

It is worth noting that searches by a combination of two or more words, for example in the dictionary definitions, can be problematic when they require the user to guess words that might appear in the definition. Although the search of feline NOT domestic in the CED yields a good list of wild felines, cat NOT house, will not. 


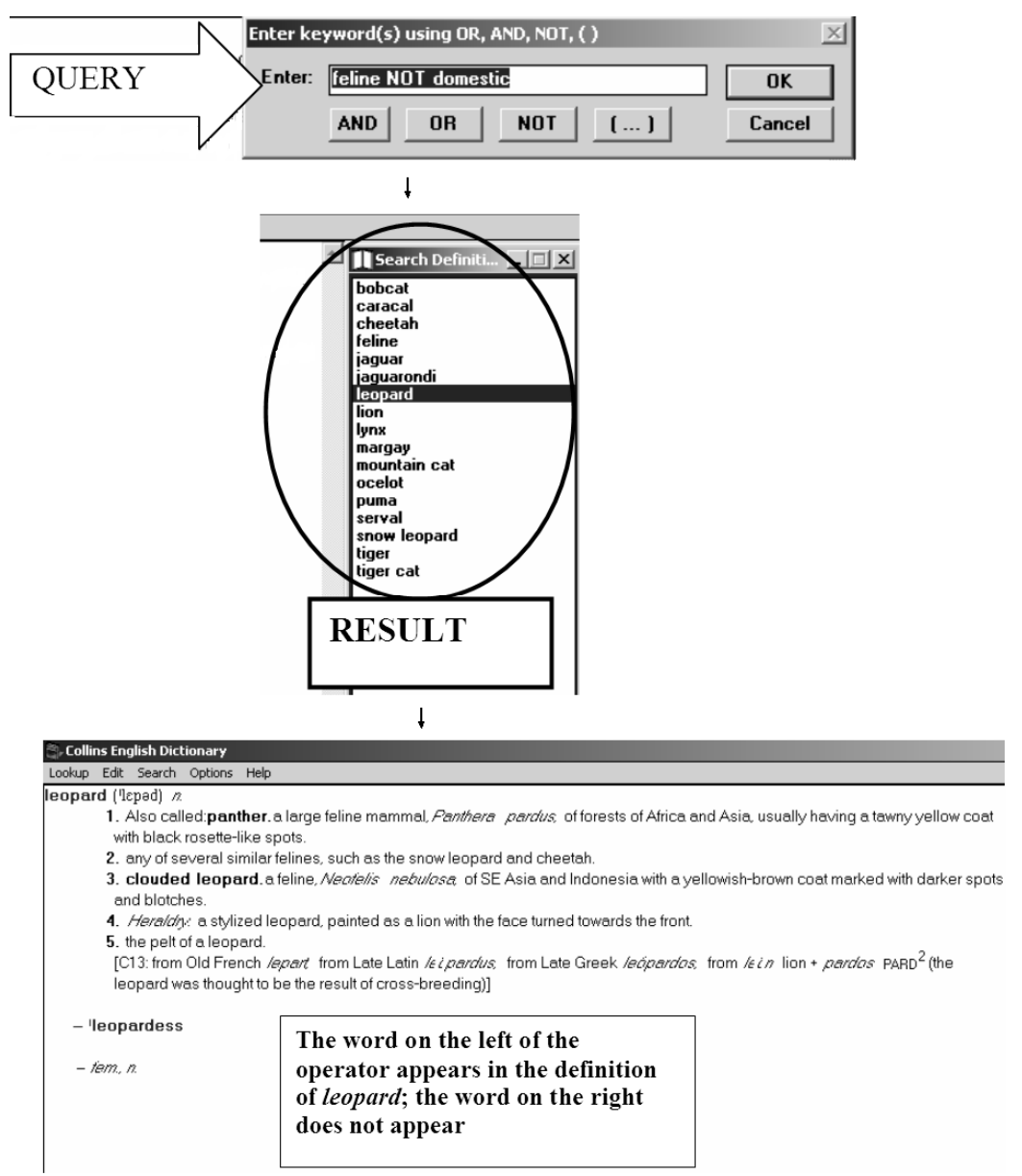

Figure 8. Presence of one word and absence of another word using operators in the $C E D$.

4.1.5.4 Presence of an exact sequence of words. Of the dictionaries analyzed, the DUE and the WordReference allow users to search for an exact sequence of words in the dictionary's content field. In both dictionaries the sequence of words must be introduced in quotation marks.

Figure 9 presents an example of a search for an exact sequence of words in the $D U E$. When we search for words whose definition includes the exact sequence felino doméstico 'domestic feline', the result is the word gato 'cat'. As we can see in figure 9 the exact sequence felino doméstico appears in the definition of gato.

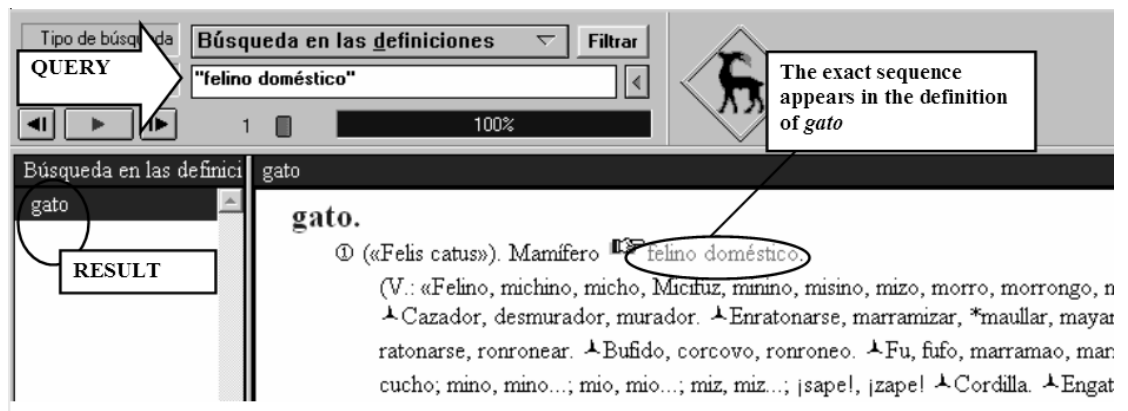

Figure 9. Presence of an exact sequence of words using operators in the $D U E$.

4.1.5.5 Questions in natural language. The last search subtype using combinations of two or more words is the introduction of questions in natural language. This search can be used to obtain a list of words that might answer the question introduced in the dictionary. 
Of the dictionaries analyzed, only the OneLook Reverse Dictionary allows this search technique. Although there is no restriction on the questions that can be introduced, the recommendation is to use wh- questions (for example starting with what is or who is). As an example, if we introduce the question what is a big building?, the dictionary retrieves a list of words including hall, block, barn, tower, castle, pile, termites, court, basilica, mausoleum, etc. The word castle is defined as a large building. In the same dictionary, if we introduce the question what is a small building?, the resulting list includes chapel, turret, shed, summerhouse, lodge, shop, dentil, coach house, portakabin, cottage, etc. The word lodge is defined as a small (rustic) house.

\section{OneLook Reverse Dictionary}

\begin{tabular}{|c|c|c|c|}
\hline \multicolumn{2}{|c|}{ Describe concep } & what is a big building? & Find wor \\
\hline $\begin{array}{l}\text { 1. } \underline{\text { hall }} \\
\text { 2. } \underline{\text { block }} \\
\text { 3. } \underline{\text { barn }} \\
\text { 4. } \underline{\text { tower }} \\
\text { 5. } \underline{\text { castle }} \\
\text { RESULt }\end{array}$ & $\begin{array}{l}\text { 6. pile } \\
\text { 7. termites } \\
\text { 8. court } \\
\text { 9. basilica } \\
\text { 10. } \\
\text { mausoleum }\end{array}$ & $\begin{array}{l}\text { Quick de } \\
\quad \text { (cas } \\
\text { noun: a } \\
\text { building for } \\
\text { occupied b } \\
\text { and fortifie } \\
\text { attack }\end{array}$ & $\begin{array}{l}\text { nitions } \\
\text { e) } \\
\text { arge } \\
\text { nerly } \\
\text { a ruler } \\
\text { against }\end{array}$ \\
\hline
\end{tabular}

\section{OneLook Reverse Dictionary}

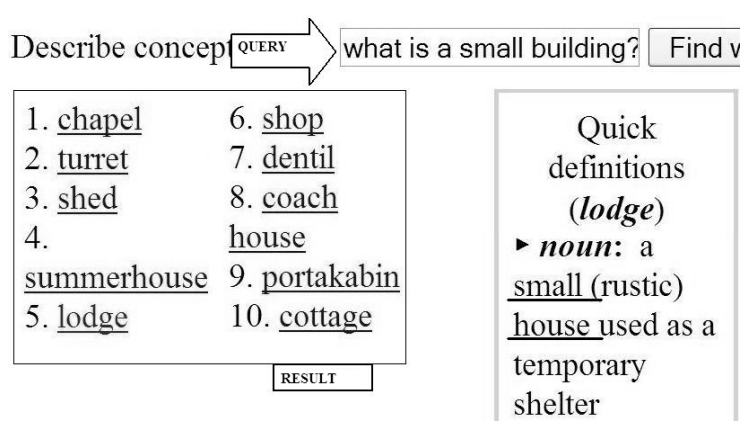

Figure 10. Questions in natural language in the OneLook Reverse Dictionary.

Searches using questions in natural language are the same as other searches with combinations of two or more words, because what the dictionary does is to extract the question keywords to look for the related words which it then retrieves. In the case of the question What is a big building?, the dictionary looks for words that are related to big and building. The dictionary also detects some more complex elements in a question, such as negations placed immediately before a word. For instance, if we introduce the question Which country has sea? in the OneLook Reverse Dictionary, the first result is seaside (a place by the sea). In contrast, if we introduce Which country has no sea?, the first result is landlocked (almost or entirely surrounded by land). However, if the negation does not appear immediately before the keyword, the system does not understand what the user wants to ask. For example, if we introduce the question Which country does not have sea?, the retrieved words are short or solid, which are not related to the question. This system does not allow the introduction of complex questions.

4.1.6 Filters. Filters are used to add a search restriction to the query, and may take the form of, for example, a part-of-speech restriction, a thematic field restriction or a language restriction (in bilingual or multilingual dictionaries). Filters can be combined with an exact word, a partial word, or an approximate word. They are useful to restrict 
the result to words of a particular part of speech or thematic area. Some dictionaries allow the user to refine the search by searching inside the search result from a previous search (refine search). Below we provide two examples of filters.

4.1.6.1 Part-of-speech filter. An example of a part-of-speech filter is to look for a word only in its noun form. The Lexical FreeNet dictionary allows the user to restrict queries to nouns, adjectives, verbs, and adverbs. As we can see in Figure 11, if we restrict the query play to the part of speech noun, the dictionary retrieves the word play when it is a noun and it does not include the verb play in the results.



Figure 11. Use of part-of-speech filters in the Lexical FreeNet dictionary.

4.1.6.2 Thematic area filter. An example of a thematic area filter is found in the Cercaterm dictionary. We introduce the word puente and we restrict the search with the thematic area filter Electrónica 'electronics'. The result is a list of words or expressions in Catalan in which puente is a type of electronic connection (pont 'jumper', establir un pont 'to jumper', pont de Schering 'Schering bridge', etc.). If we introduce the same query puente and restrict the search with the thematic area filter Transportes 'transport', the result is a list of words in which puente is a type of building, a bridge (pont 'bridge', aproximació a un pas a nivell o a un pont mòbil 'warning sign for grade crossing or a bascule or traveling bridge', etc.).








Figure 12. Use of thematic area filters in Cercaterm.

\subsection{The second element: the resource}

In an electronic dictionary the information is structured in sections or fields. Each of these sections can be queried. This feature of electronic dictionaries differs from paper dictionaries, in which information is alphabetically ordered and the only option available is to search alphabetically for a word in the list. Electronic dictionaries allow other types of search techniques: in the dictionary entries, in the content fields (definitions, examples, relations, forums or corpora), in a thematic index, and in external links (to a search engine or other dictionaries).

Broadly speaking, our classification divides the resource or specific sections that contain searchable information into four types: 1) entry field, 2) content field, 3) thematic field index, and 4) external links access field.

4.2.1 Search in the entry field. We understand entry field to mean all the headwords used to head and list the dictionary entries. The use of any query (an exact word, a partial word, etc.) in this field will allow the user to access all the entries whose headword coincides with the query introduced. A search in the entry field can be used to obtain information about a word that is found in such entries, for example, a definition, grammatical information, a usage example, etc. A single entry can also contain several sub-entries where each sub-entry has its own entry field. For example, an entry may contain the main entry (that may contain spelling variants, variants, derived words and phrases plus inflections of all types of headwords), as well as one or more sub-entries containing idioms and phrasal verbs.

A word can be looked up in alphabetical order in the entries. For example, in the $O E D$, the word look-up search option orders the list of dictionary entries starting with the word or sequence of characters introduced by the user. If we introduce the sequence hous, the list starts with the word housage, which is the first word in the dictionary that starts with hous. 


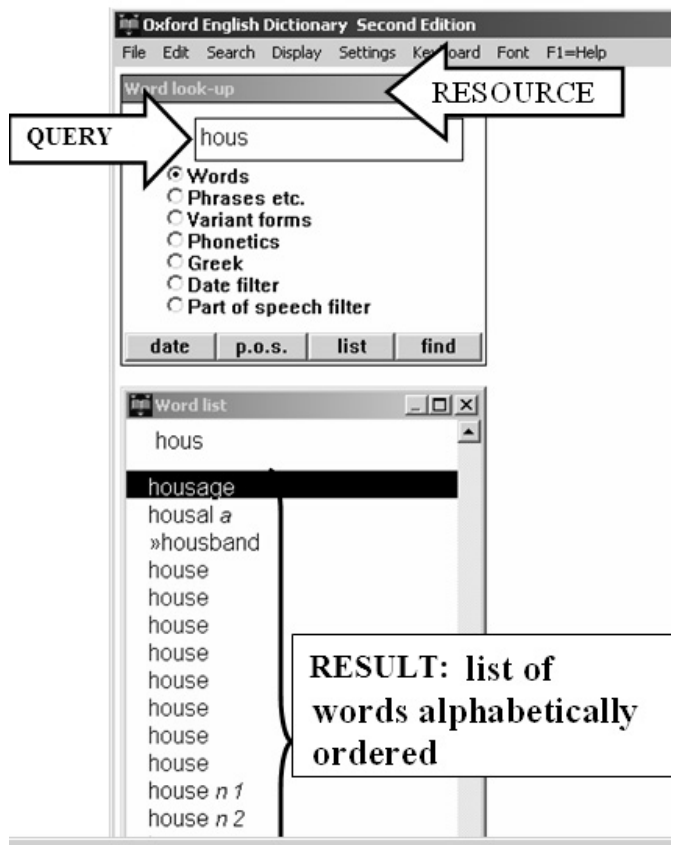

Figure 13. Search in the alphabetical list of entries in $O E D$.

Some dictionaries allow the list of entries to be ordered inversely, starting with the last letter introduced. For example, if we introduce the sequence of characters cción with the option diccionario inverso in the DRAE, the list of entries begins with the word acción 'action', the first word in alphabetical order ending in cción, and is followed by others such as redacción 'writing', reacción 'reaction', facción 'faction', etc.

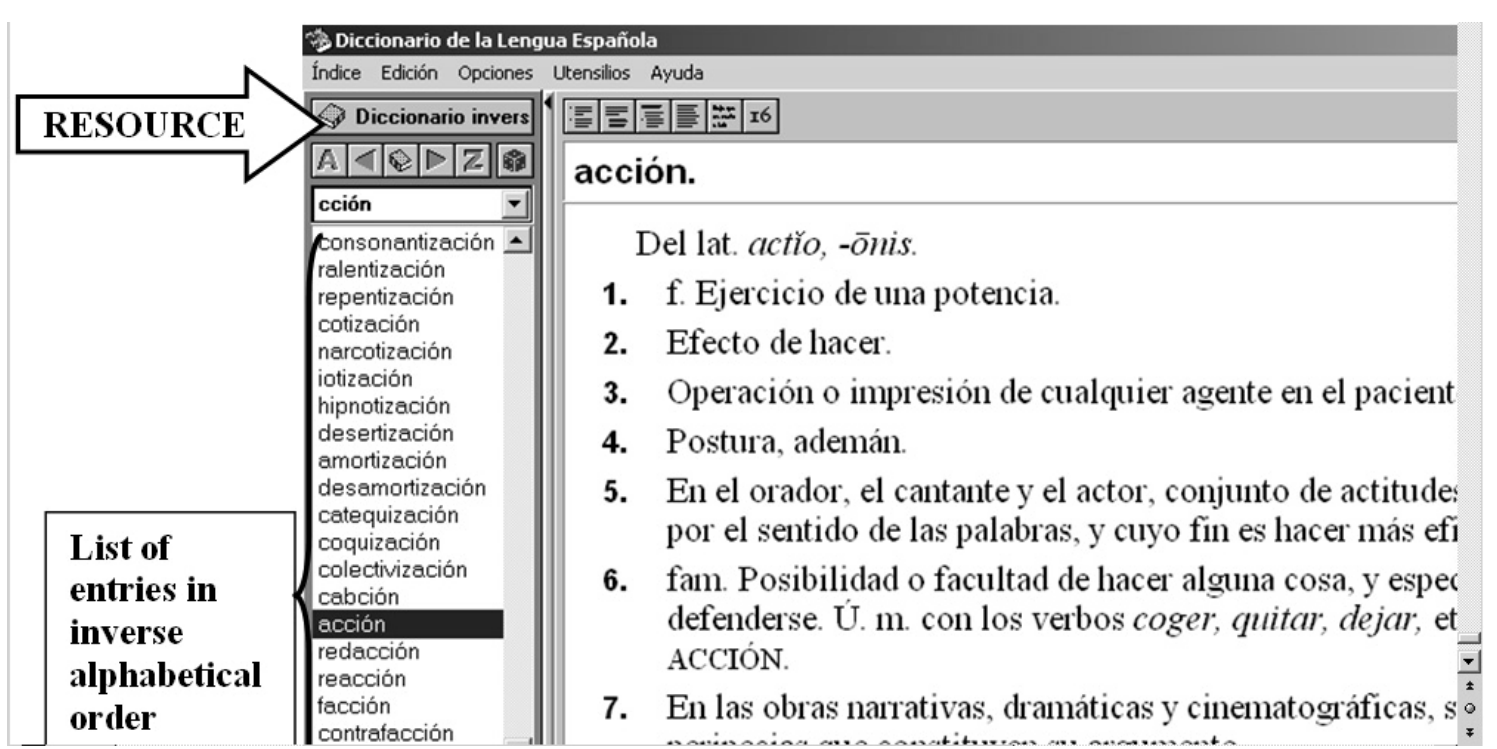

Figure 14. Search in the inverse alphabetical list of entries in the DRAE.

4.2.2 Search in the content field. Content fields include information in text format on each entry. The information can vary: a definition, examples, lexical or semantic relations, comments from a forum, and corpus concordances. The user can search with queries in these content fields to find entries whose content coincides with the query introduced. Below we provide examples of searches in the content fields mentioned.

4.2.2.1 Search in the definition fields. In this example, we look for the words fruit and yellow in the definition fields of the Wordsmyth dictionary. The dictionary retrieves a 
list of words agrimony, apple, apricot, cherry, chinaberry, citron, Golden Delicious, grapefruit, Japanese quince, jujube and lemon. Figure 15 shows the definitions to the right of these words in which the words fruit and yellow appear. The DUE, OED, CED, WordReference and OneLook Reverse Dictionary also provide this search technique option.



Figure 15. Search in the definition fields of the Wordsmyth.

4.2.2.2 Search in the relations fields. Some dictionaries incorporate information on semantic relations (for example synonymy, antonymy, hypernymy, etc.) or lexical relationships (for example collocations) among their words or terms. These relation fields include words or expressions with a lexical or semantic relation to a dictionary entry. In many cases, this information can be accessed by navigating the dictionary's hyperlinks or by a direct search using keywords. In the search by navigation, the user accesses synonyms of a word that are linked from within an entry, and which can lead to other synonyms. In the direct search with keywords, the dictionary searches for the query word or words in the synonymy fields, and retrieves a list of entries that include that synonym in their synonymy fields. Below we include examples of both search techniques.

In our example of a search in the relations fields by navigation in the MerriamWebster monolingual English dictionary, the entries contain hyperlinks to related words. As we can see in Figure 16, the entry for agreement is linked to the semantically related words concord, compact and treaty.

Main Entry: agree-ment (1)

Pronunciation: $\downarrow$-'grē-mənt
Function: noun
Date: 15 th century
$1 \mathrm{a}:$ the act or fact of agreeing $\mathbf{b}:$ harmony of exinion, action, or character :
CONCORD

$2 \mathbf{a}:$ an arrangement as to a course of action $\mathbf{b}: \underline{\text { COMPACT, TREATY }}$

$3 \mathbf{a}:$ a contract duly executed and legally binding $\mathbf{b}:$ the language or instrument

embodying such a contract

Figure 16. Search in the semantic relations fields by navigation in the Merriam-Webster monolingual English dictionary. 
Another example of a search in the relations field by navigation comes from the WordNet dictionary. These dictionary entries include semantically related words, such as synonyms, hypernyms, hyponyms, etc. As we can see in Figure 17, the entry for the word transport accesses the hyponyms air transport, navigation, hauling or trucking, etc.

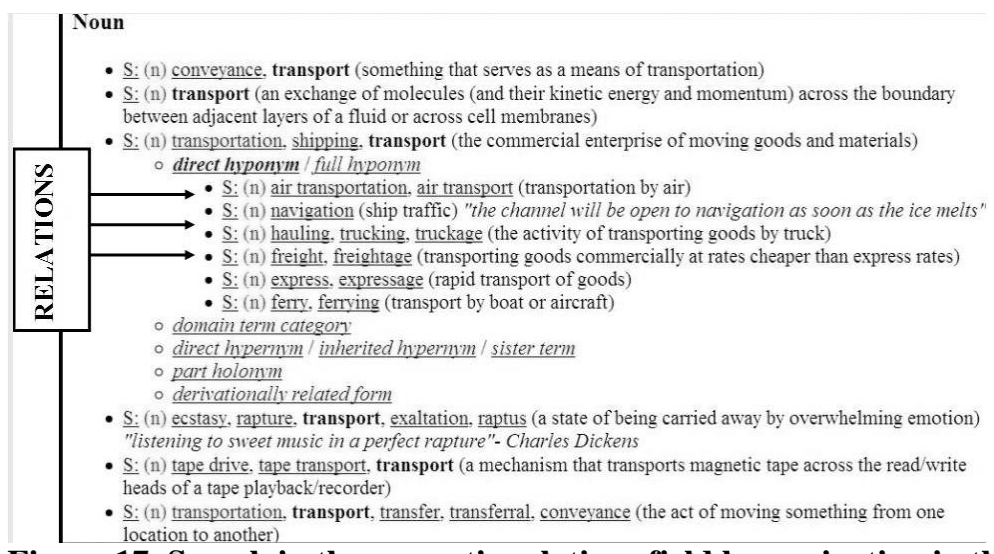

Figure 17. Search in the semantic relations field by navigation in the WordNet dictionary.

An example of direct search with keywords in the semantic relations field can be found in the Wordsmyth dictionary. Figure 18 shows a search for entries that include the word agreement among their synonyms. The dictionary retrieves a list of 27 synonyms for agreement, including accession, accord, alliance, etc.



Figure 18. Direct search in the semantic relations in the Wordsmyth dictionary.

Other dictionaries also allow searches in the semantic relations fields. The WordReference dictionary contains a Spanish synonym search option. This dictionary also includes links to related entries. The OneLook Reverse Dictionary generates lists of words related to the query. In the Ultralingua dictionary, the user introduces a word and the dictionary can search for its synonyms or related words.

Lexical FreeNet allows two types of searches in the semantic relations field. Firstly, words related to one term; for example, if we introduce the word falcon, the dictionary option show related retrieves the related words pigeons, nest, hawk, hunt, American kestrel, caracara, falco columbarius, falco peregrinus. Every word in the list is related to the term falcon (synonymy relation, generalization, specialization, etc.). 
Secondly, this dictionary can retrieve words that are related at the same time to two query words (connection option). As we can see in Figure 19, a word that is related both to agreement and lawsuit is settlement.

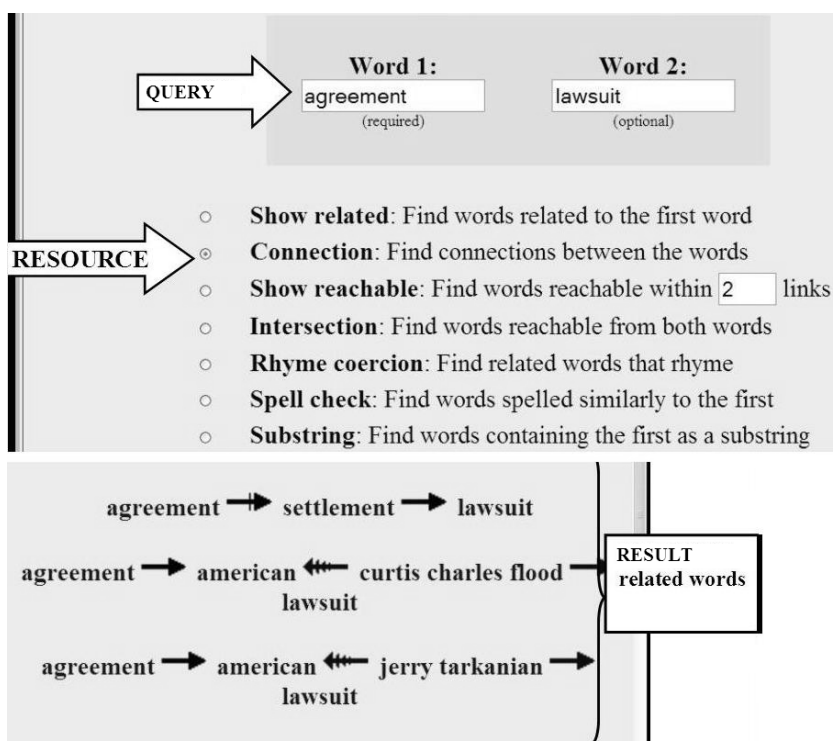

Figure 19. Direct search in semantic relations in the Lexical FreeNet dictionary.

Some dictionaries allow searches for lexical relations, for instance term collocations. In the Computer Science dictionary, DiCoInfo, we introduce the verb envoyer and search in the lien lexical (lexical relation) field. The result is a list of dictionary entries that contain field collocations in French of the verb envoyer in their

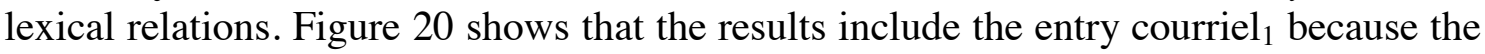
collocation envoyer un courriel is contained in its lexical relations field, or the entry spam $_{1}$, contained in the collocation envoyer un spam à.



Figure 20. Search in the lexical relations field in the DiCoInfo dictionary. 
4.2.2.3 Search in a complementary forum. Some dictionaries incorporate forums in their content fields. In these forums the user can ask questions related to the entry or consult the answers to previous questions made by other users. These forums can be useful when the information included in the entry does not satisfy the user's doubts. For example, in the WordReference dictionary, the entries for agreement and contract include a comment from the forum contract for agreement in which the difference between a contract and an agreement is explained.

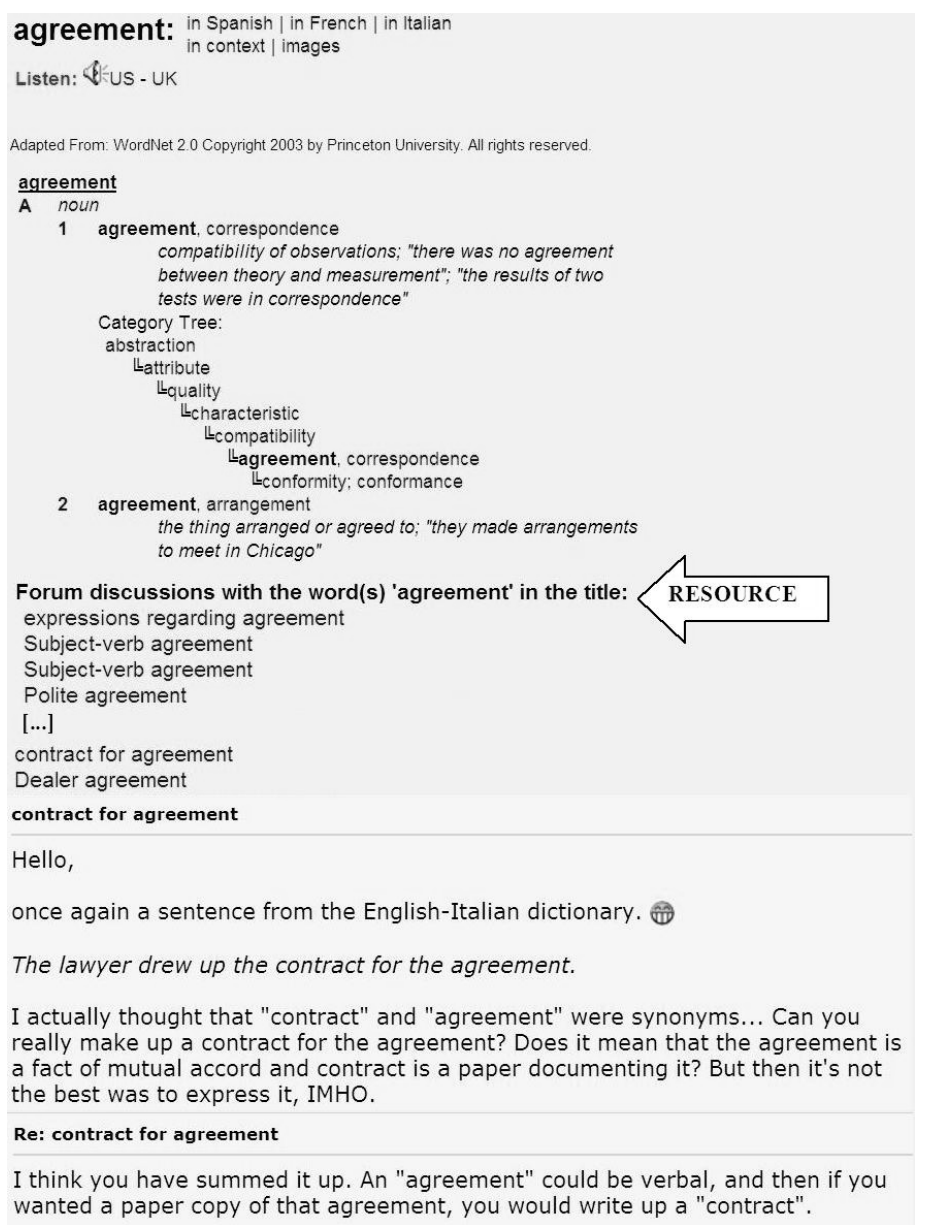

Figure 21. Search in a complementary forum in the WordReference dictionary.

Forums can be useful for both dictionary users and creators, since the latter can use the users' doubts and answers to improve the dictionary. This way the forum works as a control and evaluation mechanism and allows creators to adapt the dictionary to the users' needs. However, this search technique has to be used with caution: answers in a forum are not always controlled, and their reliability should be verified.

4.2.2.4 Search in a complementary corpus. Some dictionaries incorporate links to a corpus in the entry content, in which the user can access concordances for each dictionary entry. An example of this search technique can be found in the EOHS Term database. Figure 22 shows this database entry for the term employee. Above the entry is a tab marked Concordances, which provides a list of 333 concordances of the term employee. The user can read each concordance, and also access the complete text in which the concordance appears, by clicking on the icon to the right of each concordance. 


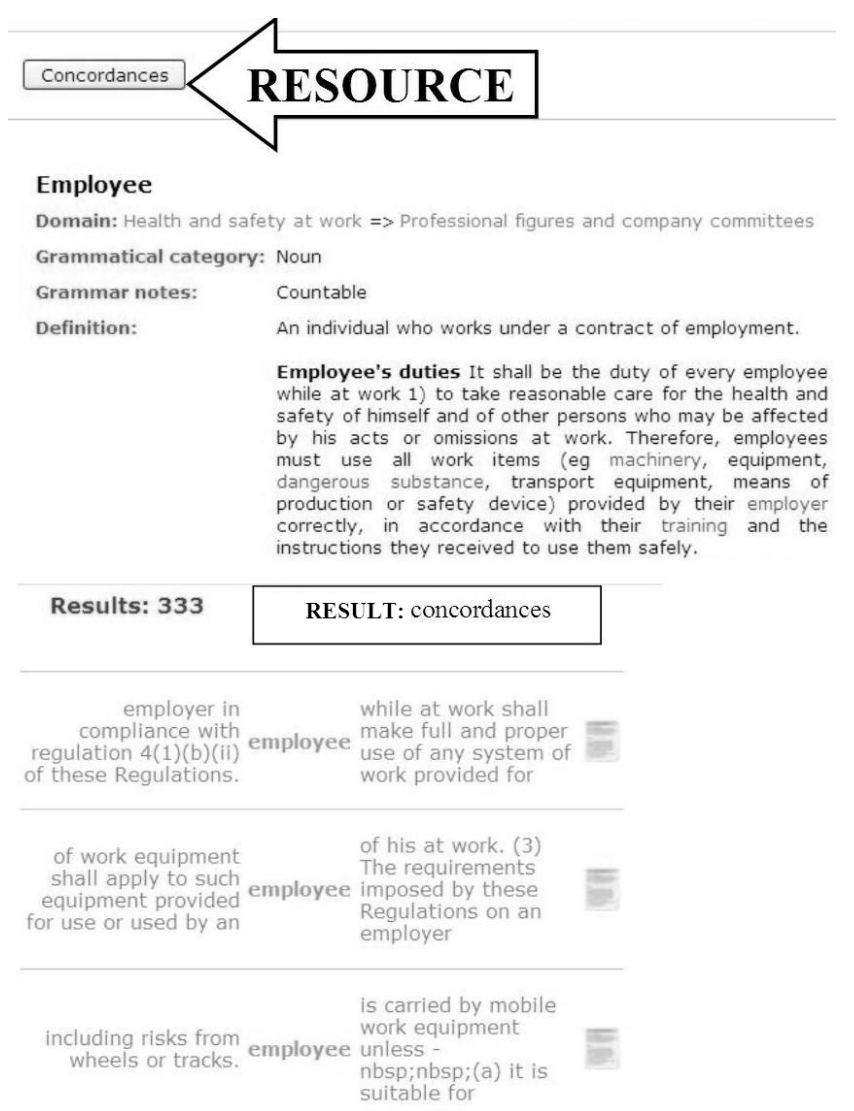

Figure 22. Search in a complementary corpus in the EOHS Term dictionary.

4.2.3 Search in the thematic field index. A thematic field index is a list of hierarchically ordered areas, in which the user can navigate and select the item they want to consult. This field is frequently used to show a map of thematic areas. The dictionary entries, which can be words, but may also be images, are classified in these thematic areas. There are two types of search in the thematic field index. In the search by navigation the user scrolls down the hierarchical structure of thematic areas. In the direct search the user introduces a keyword in the dictionary that corresponds to a thematic area. Examples of both types of search are given below.

In the first example we search by navigation in the $D R A E$ thematic field index. We scroll down the profesiones y disciplinas 'professions and disciplines' hierarchical structure, then enter ciencia y técnica 'science and technology', matemáticas 'mathematics' and finally álgebra 'algebra'. The result is a list of dictionary entries classified within the selected thematic area that includes the terms binomio 'binomial', cociente 'quotient', coeficiente 'coefficient', combinación 'permutation', etc. 


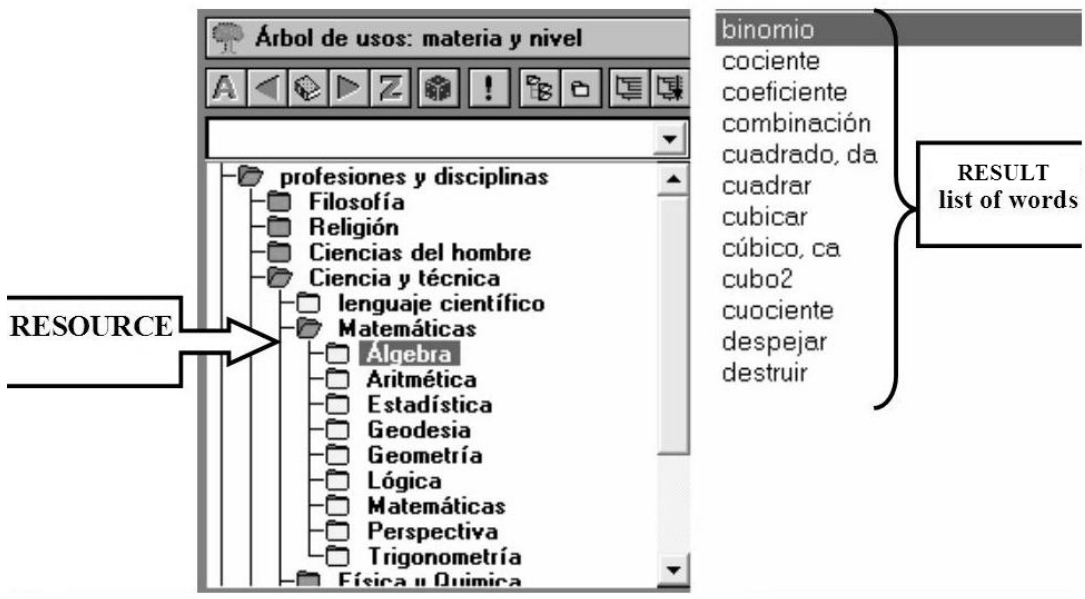

Figure 23. Search in the $D R A E$ thematic field index.

In the following example we perform a direct search with keywords in the thematic field index of the Merriam-Webster visual dictionary. We introduce the keyword flower. The dictionary suggests the thematic areas flower and flowering. If we select the area flower we access entries with images related to this thematic area, such as pleasure garden, examples of flowers, structure of a flower, structure of a plant, etc.



Figure 24. Direct search with keywords in the Merriam-Webster visual dictionary thematic field index.

4.2.4 Search in external links access field. This type of field offers links to resources external to the dictionary. Some dictionaries are linked to web search engines and other dictionaries.

For example, in the WordReference dictionary, the in context option searches in Google for the query introduced. In addition, the images option will search for the query in Google images.

Our example of a search in links to external dictionaries comes from the OneLook Reverse Dictionary. Figure 25 shows that the entry for the word hall has links to other general online dictionaries, such as the American Heritage Dictionary of the English Language or the Cambridge International Dictionary of English, as well as other specialized online dictionaries in the fields of arts, economy, computer science, medicine, etc. 


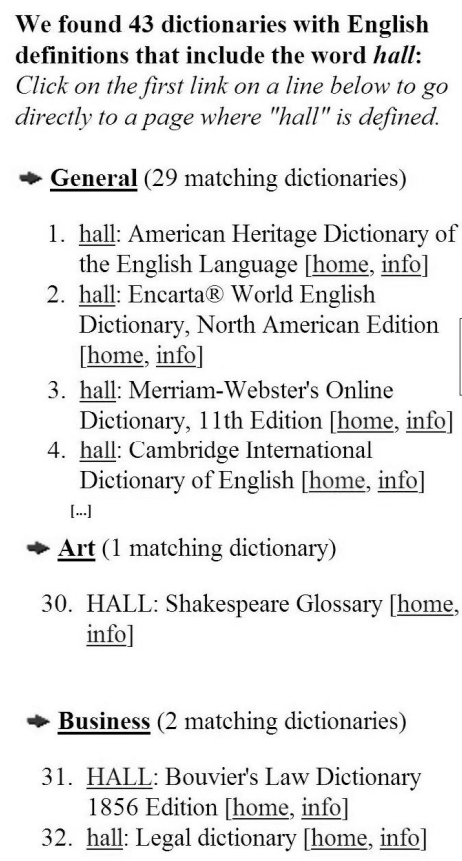

Figure 25. Search in the external links access field of the OneLook Reverse Dictionary.

\subsection{The third element: the result}

The result of a search is the information the user obtains after querying a dictionary. The result of a dictionary search is usually the entry with information about a word (meaning, grammatical information, pronunciation, etymology, use in context, equivalences, etc.). In other cases, the result is a word or a list of words that corresponds to an entry in the dictionary. Finally, the result may also be an image or list of images, and the results may also include audio files. The retrieval of these results depends on the type of dictionary and the options incorporated in it. Below we describe what we consider to be the most innovative results as implemented in electronic dictionaries.

4.3.1 Context/s. We start by explaining the result where the user obtains information about the use in context of a word. Some dictionaries include contextual information about words in their entry content fields. The DiCoInfo dictionary contains a contextual field in which the user can access concordances extracted from a corpus. Figure 26 shows that the entry for backup has three contexts with their references to the corpus file from which the contexts were obtained.



Figure 26. Result of 'use in context' information in the DiCoInfo dictionary.

The entries in FrameNet also include contextual information about words. Figure 27 shows the entry for the verb play in the frame performers_and_roles. All the frame elements that have been annotated in the contexts of play are included in a table. Each 
frame element has a different color, which allows the user to identify every frame element in a context.

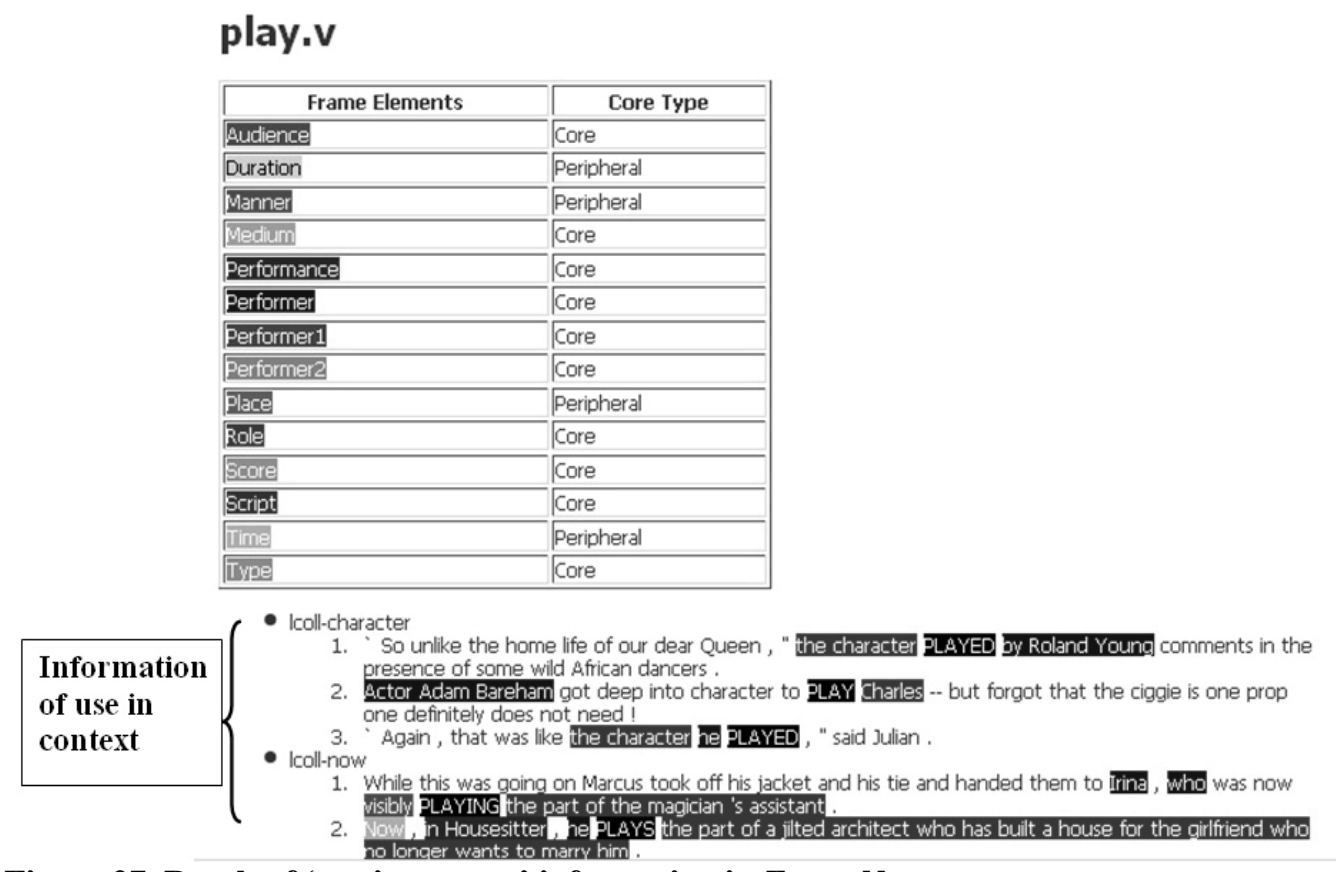

Figure 27. Result of 'use in context' information in FrameNet.

The user can also obtain contextual information about the dictionary entries by accessing the concordances of a complementary corpus. Figure 28 presents the concordances for the word corrosive in the EOHS Term database. These concordances can be accessed by clicking on the dictionary entry for corrosive.

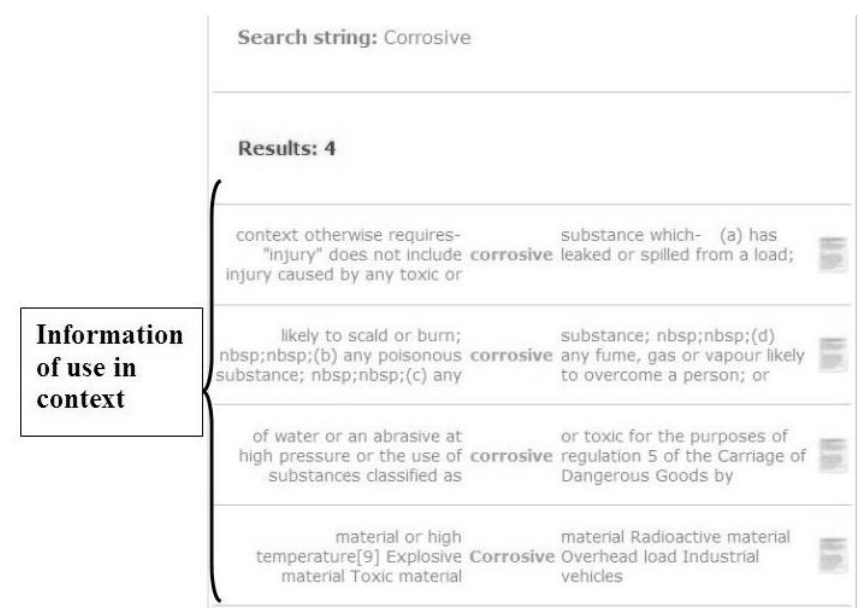

Figure 28. Result of 'use in context' information in the EOHS Term database.

4.3.2 Word or list of words. Another result obtained from the dictionary is a word or list of words. Some search techniques, such as the search in content fields or the search in a thematic field index, can generate a list of words. For example, if we search the query vehicle in the definition field of the Wordsmyth dictionary, it retrieves a list of words that contain the query in the definition fields of their entries, such as aircraft, airflow, ambulance, aquaplane, ATV, automobile, etc.

In addition, if we search for the thematic area Lógica 'Logic' in the DRAE thematic field index (profesiones y disciplinas 'Professions and disciplines' $\rightarrow$ Filosofía 
'Philosophy' $\rightarrow$ Lógica 'Logic'), the result we obtain is a list of words that are classified within this field, such as a contrariis 'e contrario', ad hóminem 'ad hominem', antecedente 'antecedent', a pari 'a pari', apodíctico 'apodictic', argumento 'argument', etc.

It is worth mentioning that in the dictionaries that we have analyzed, lists of words are displayed in alphabetical order. However, it would be useful to the user if the dictionary displayed search results in order of relevance according to the user's search. For example, if the user searches for agency, the resulting list of words should not be displayed in the order in which they appear in the dictionary, but in relevance order so that agency appears in the search result list before adoption agency.

4.3.3 Image or list of images. Some visual dictionaries retrieve images classified in a thematic field index. For example, in the Merriam-Webster visual dictionary, if we navigate in the thematic field (themes) in Plants \& gardening $\rightarrow$ Plants $\rightarrow$ Flower $\rightarrow$ Structure of a flower, the dictionary retrieves the image of a flower with the names of all its parts.

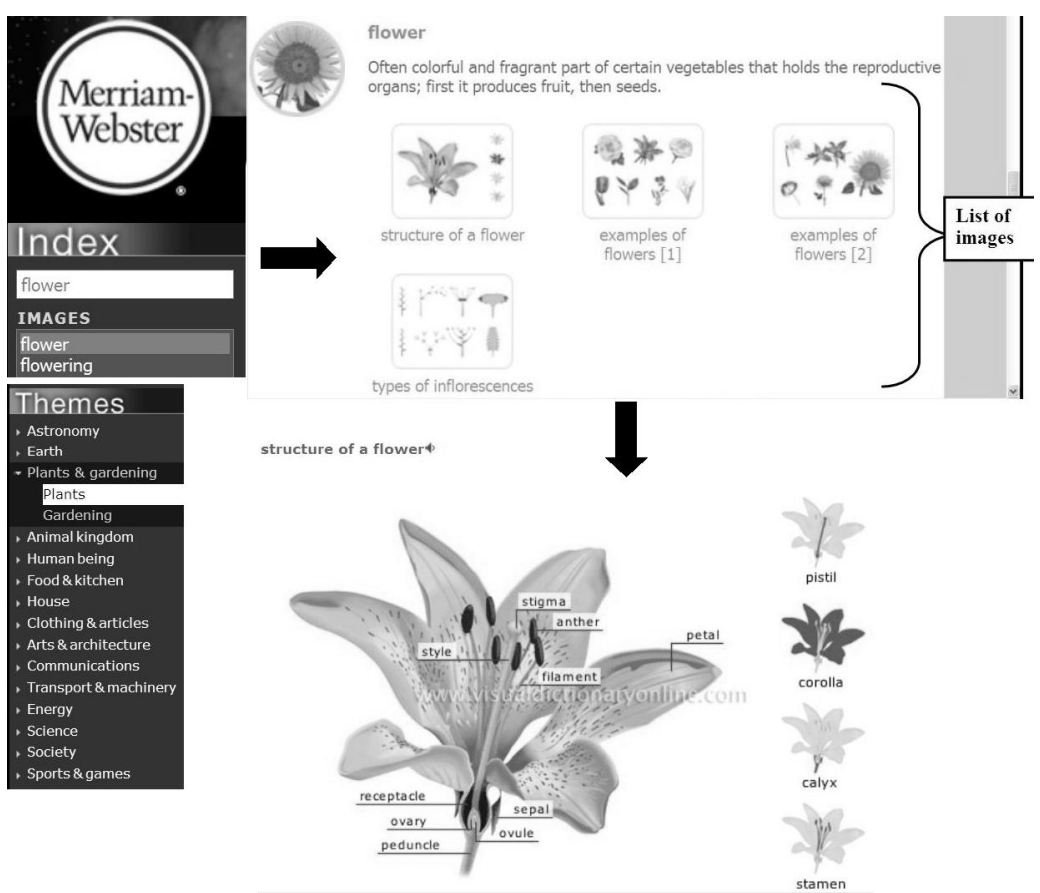

Figure 29. Result of image or list of images in the Merriam-Webster visual dictionary.

4.3.4 Audio files. It is becoming common among electronic dictionaries to include audio files in the entries of some terms. In most dictionaries these audio files provide the pronunciation of words. Other types of audio files are also available in some electronic dictionaries. Some audio files help the user to understand the meaning of a word, in the same way as a definition or an image can do. For example, in the Macmillan English Dictionary some entries include audio files that clarify the meaning of a word with a sound. In the entry of the noun applause, we can hear the sound of people applauding, thus helping the user to understand the meaning of that word.

\section{Summary table and conclusion}


In the analysis presented in sections 2 and 3, we have shown how each electronic dictionary uses a different nomenclature to refer to the types of searches it offers. Moreover, in some cases the same name is used in different dictionaries to refer to different searches. This inevitably leads to problems when comparing dictionaries or teaching students how to use them. Neither does this situation encourage communication between lexicographers, terminographers and computer technicians when collaborating to develop a new dictionary, nor assist faculty in teaching future lexicographers, terminographers, philologists, or translators to use a standard classification that is valid for all the search techniques.

A homogeneous classification and nomenclature must therefore be established to evaluate electronic dictionaries, assess their functions, teach how to use them, or design new dictionaries. Our search techniques classification can be applied to the assessment of any dictionary. In addition, it is flexible in that new elements can be incorporated.

From the review of the literature and the analysis of a set of electronic dictionaries, we have synthesized the search techniques in electronic dictionaries in three elements: the query, the resource, and the result. These three elements embody all the search possibilities we have observed in electronic dictionaries. With this classification, we aim to contribute to solving the problems related to nomenclatures, types and subtypes of searches that we have found in each particular dictionary.

Table 2. Summary of our search techniques classification for electronic dictionaries.

\begin{tabular}{|c|c|c|}
\hline QUERY & RESOURCE & RESULT \\
\hline $\begin{array}{l}\text {-Exact word (house) } \\
\text {-Partial word (hous*) } \\
\text { - Approximate word (setelment) } \\
\text { - Anagram or crossword search } \\
\text { (bowle = bowel, below, elbow) } \\
\text { - Combination of two or more } \\
\text { words (fruit, yellow and acid) } \\
\text {-Filters } \\
\text { oPart of speech (noun, } \\
\text { verb, adjective, etc.) } \\
\text { oThematic area } \\
\text { (electronics, transport) } \\
\text { oLanguage }\end{array}$ & $\begin{array}{l}\text { •Entry field (alphabetical } \\
\text { index) } \\
\bullet \text { Content fields } \\
\text { (definitions, examples, } \\
\text { relations, complementary } \\
\text { forums or corpora, etc.) } \\
\text { - Thematic field index } \\
\text { - External links access } \\
\text { field }\end{array}$ & $\begin{array}{l}\text {-Information about } \\
\text { meaning } \\
\text {-Grammatical } \\
\text { information } \\
\text {-Pronunciation } \\
\text {-Etymological } \\
\text { information } \\
\text {-Information about } \\
\text { equivalences } \\
\text {-Information about use in } \\
\text { context } \\
\text {-Word or list of words } \\
\text {-Image or list of images } \\
\text {-Audio files }\end{array}$ \\
\hline
\end{tabular}

\section{Acknowledgements}

This research is part of the ONTODIC Project: Metodología y tecnologías para la elaboración de diccionarios onomasiológicos basados en ontologías. Recursos terminológicos para la e-traducción (Methodology and technologies for the elaboration of onomasiological dictionaries based on ontologies. Terminological resources for etranslation), TSI2006-01911, and the ONTODIC II Project: Metodología y técnicas para elaborar diccionarios de colocaciones basados en ontologías. Recursos terminológicos para la e-Traducción (Methodology and techniques for the elaboration 
of collocations dictionaries based on ontologies. Terminological resources for etranslation), TIN2009-07690, both funded by the Spanish Government.

\section{Notes}

${ }^{1}$ The base form of a word is the lemma of that word, which normally corresponds to the headword of a dictionary entry (Pérez, 2002a).

${ }^{2}$ English and Spanish versions of this dictionary are currently under development.

3 This dictionary and all its functions are described in greater detail in Beeferman (1998).

${ }^{4}$ Fellbaum (1998) uses different names to refer to this database.

\section{References}

\section{A. Electronic dictionaries}

Cercaterm, Centre de Terminologia TERMCAT <http://www.termcat.cat/>

Collins English Dictionary, Electronic Edition. Version 1.5, HarperCollins Publishers.

Diccionario de la lengua española, Electronic Edition. Version 21.1.0., Real Academia Española. Madrid, Espasa Calpe.

Diccionario de la lengua española, 22nd Edition, Real Academia Española $<$ http://rae.es $>$

Diccionario de uso del español, María Moliner. Madrid, Gredos.

DiCoInfo (Dictionnaire fondamental de l'informatique et de l'Internet), Observatoire de Linguistique Sens-Texte, Université de Montreal $<$ http://olst.ling.umontreal.ca/dicoinfo/>

EOHS Term, Advanced School of Modern Languages for Interpreters and Translators (SSLMIT), University of Bologna $<$ http://eohsterm.org/sections/terminology/index.php>

FrameNet <http://framenet.icsi.berkeley.edu/>.

Lexical FreeNet, Version 2.0. <http://www.lexfn.com/>.

Macmillan English Dictionary, Macmillan Publishers Limited $<$ http://www.macmillandictionary.com/>

Merriam-Webster Online <http://www.merriam-webster.com/>

OneLook Reverse Dictionary <http://www.onelook.com/reverse-dictionary.shtml>

Oxford English Dictionary, Electronic Edition. Second Edition. Version 1.00, Oxford University Press.

Ultralingua $<$ http://ultralingua.com/onlinedictionary/index.html $>$

WordNet 3.0. Princeton University <http://wordnet.princeton.edu/obtain >

WordReference Online Language Dictionaries <http://wordreference.com/>

Wordsmyth <http://www.wordsmyth.net/>

\section{B. Other literature}

[1] Abate, F. R. 1985. 'Dictionaries Past \& Future: Issues and Prospects.' Dictionaries 7: 270-83.

[2] Alcina, A. 2009. 'Metodología y tecnologías para la elaboración de diccionarios terminológicos onomasiológicos.' In A. Alcina, E. Valero, and E. Rambla (eds.), Terminología y sociedad del conocimiento. Bern: Peter Lang, 33-58.

[3] Atkins, B. T. S. and K. Varantola. 1998. 'Monitoring Dictionary Use.' In B. T. S. Atkins (ed.), Using Dictionaries. Studies of Dictionary Use by Language Learners and Translators. Tübingen: Max Niemeyer, 83-122. 
[4] Beeferman, D. 1998. 'Lexical Discovery with an Enriched Semantic Network.' In S. Harabagiu (ed.), Proceedings of the Workshop on Applications of WordNet in Natural Language Processing Systems, ACL/COLING, 135-41.

[5] Béjoint, H. 1981. 'The Foreign Student's Use of Monolingual English Dictionaries: A Study of Language Needs and Reference Skills.' Applied Linguistics 2.3: 207-22.

[6] Béjoint, H. 1989. 'The Teaching of Dictionary Use: Present State and Future Tasks.' In F. J. Hausmann, O. Reichmann, E. Wiegand, and L. Zgusta (eds.), Wörterbücher/Dictionaries/Dictionnaires, Ein internationales Handbuch zur Lexikographie/An International Encyclopedia of Lexicography/Encyclopédie internationale de lexicographie, 1. Berlin: Walter de Gruyter, 208-15.

[7] Bogaards, P. 1988. 'À propos de l'usage du dictionnaire de langue étrangère.' Cahiers de lexicologie 52.1: 131-52.

[8] Bowker, L. 1998. 'Using Specialized Monolingual Native-Language Corpora as a Translation Resource: A Pilot Study.' Meta 43.4: 631-51.

[9] Carr, M. 1997. 'Internet Dictionaries and Lexicography.' International Journal of Lexicography 10.3: 209-30.

[10] Castagnoli, S. 2008. 'Corpus et bases de données terminologiques: l'interpretation au service des usagers.' In F. Maniez, P. Dury, N. Arlin, and C. Rougemont (eds.), Corpus et dictionnaires de langues de spécialité. Bresson: Presses Universitaires de Grenoble, 213-30.

[11] Colominas, C. 2004. 'Los corpora como herramientas de traducción.' In E. Ortega (ed.), Panorama actual de la investigación en Traducción e Interpretación. Granada: Atrio, 362-72.

[12] Corpas, G., J. Leiva, and M. J. Varela. 2001. 'El papel del diccionario en la formación de traductores e intérpretes: análisis de necesidades y encuestas de uso.' In M. Ayala (ed.), Diccionarios y enseñanza. Alcalá de Henares: Servicio de Publicaciones de la Universidad de Alcalá, 239-73.

[13] Corris, M., C. D. Manning, S. Poetsch, and J. Simpson. 2000. 'Bilingual Dictionaries for Australian Languages: User Studies on the Place of Paper and Electronic Dictionaries.' In U. Heid, S. Evert, E. Lehmann, and C. Rohrer (eds.), Proceedings of the Ninth Euralex International Congress, EURALEX 2000, Stuttgart, Germany, August 8th-12th, 2000. Stuttgart: Institut für Maschinelle Sprachverarbeitung, Universität Stuttgart, 169-81.

[14] Cowie, A. P. 1999. English Dictionaries for Foreign Learners - A History, Oxford: Clarendon Press.

[15] Church, K. W. 2008. 'Approximate Lexicography and Web Search.' International Journal of Lexicography 21.3: 325-36.

[16] de Schryver, G. M. 2003. 'Lexicographers' Dreams in the Electronic-Dictionary Age.' International Journal of Lexicography 16.2: 143-99.

[17] Dodd, W.S. 1989. 'Lexicomputing and the Dictionary of the Future.' In G. James (ed.), Lexicographers and Their Works. (Exeter Linguistic Studies 14.) Exeter: Exeter University Press, 83-93.

[18] Faber, P., P. León, J. A. Prieto, and A. Reimerink. 2007. 'Linking Images and Words: the Description of Specialized Concepts.' International Journal of Lexicography 20.1: 39-65.

[19] Fellbaum, C. 1998. WordNet: An Electronic Lexical Database, Cambridge (Massachusetts): MIT Press. 
[20] Fernández-Pampillón, A. and M. Matesanz. 2003. 'Los diccionarios electrónicos: hacia un nuevo concepto de diccionario.' In C. López and A. Séré (eds.), Nuevos géneros discursivos: los textos electrónicos. Madrid: Biblioteca nueva, 137-58.

[21] Fillmore, C. J. 1985. 'Frames and the Semantics of Understanding.' Quaderni di Semantica 6: 222-53.

[22] Fillmore, C. J. and B. T. S. Atkins. 1998. 'FrameNet and Lexicographic Relevance.' In A. Rubio, N. Gallardo, R. Castro, and A. Tejada (eds.), Proceedings of the ELRA Conference on Linguistic Resources. Granada, 417-23.

[23] Fillmore, C. J., C. F. Baker, and H. Sato. 2002. 'The FrameNet Database and Software Tools.' In M. G. Rodríguez and C. P. S. Araujo (eds.), Proceedings of the Third International Conference on Language Resources and Evaluation (LREC). Las Palmas de Gran Canaria, 1157-60.

[24] Fillmore, C. J., C. R. Johnson, and M. R. L. Petruck. 2003. 'Background to FrameNet.' Special Issue on Frame Semantics. International Journal of Lexicography 16.3: 235-50.

[25] Forget, N. 1999. Les dictionnaires électroniques dans l'optique de la traduction. MA Dissertation, University of Ottawa.

[26] Fraser, J. 1999. 'The Translator and the Word: The Pros and Cons of Dictionaries in Translation.' In G. Anderman and M. Rogers (eds.), Word, Text, Translation. Liber Amicorum for Peter Newmark. England: Multilingual Matters, 25-34.

[27] Geeraerts, D. 2000. 'Adding Electronic Value. The Electronic Version of the Grote Van Dale.' In U. Heid, S. Evert, E. Lehmann, and C. Rohrer (eds.), Proceedings of the Ninth Euralex International Congress, EURALEX 2000, Stuttgart, Germany, August 8th-12th, 2000. Stuttgart: Institut für Maschinelle Sprachverarbeitung, Universität Stuttgart, 75-84.

[28] Gómez González-Jover, A. 2005. Terminografía, lenguajes profesionales y mediación interlingüística. Aplicación metodológica al léxico especializado del sector industrial del calzado y de las industrias afines. $\mathrm{PhD}$ Thesis, Universidad de Alicante.

[29] Gross, G. 1997. 'La grammaire, les dictionnaires et l'informatique.' In J. Pruvost (ed.), Les dictionnaires de la langue française et l'informatique. Actes du colloque la Journée des dictionnaires. Cergy-Pontoise: Centre de Recherche Texte-Histoire, 55-64.

[30] Hamon, T. and A. Nazarenko. 2001. 'Detection of Synonymy Links between Terms.' In D. Bourigault, C. Jacquemin, and M.-C. L'Homme (eds.), Recent Advances in Computational Terminology. Amsterdam/Philadelphia: John Benjamins, 185-208.

[31] Harley, A. 2000. 'Cambridge Dictionaries Online.' In U. Heid, S. Evert, E. Lehmann, and C. Rohrer (eds.), Proceedings of the Ninth Euralex International Congress, EURALEX 2000. Stuttgart, Germany, August 8th-12th, 2000. Stuttgart: Institut für Maschinelle Sprachverarbeitung, Universität Stuttgart, 85-88.

[32] Hartmann, R. R. K. 1999. 'Thematic Report 2. Case Study: The Exeter University Survey of Dictionary Use.' In R. R. K. Hartmann (ed.), Dictionaries in Language Learning. Recommendations, National Reports and Thematic Reports from the TNP Sub-Project 9: Dictionaries. Berlin: Freie Universität Berlin, 36-52.

[33] Hulstijn, J. H. and B. T. S. Atkins. 1998. 'Empirical Research on Dictionary Use in Foreign-Language Learning: Survey and Discussion.' In B. T. S. Atkins (ed.), Using Dictionaries. Studies of Dictionary Use by Language Learners and Translators. Tübingen: Max Niemeyer, 7-19.

[34] Ide, K. 1993. 'A Catalogue of Electronic Dictionaries.' Language 22.5: 42-49.

[35] Jacquet-Pfau, C. 2002. 'Les dictionnaires du français sur cédérom.' International Journal of Lexicography 15.1: 89-104. 
[36] Kaalep, H.-J. and J. Mikk. 2008. 'Creating Specialised Dictionaries for Foreign Language Learners: A Case Study.' International Journal of Lexicography 21.4: 369-94. [37] Kay, M. 1984. 'The Dictionary Server.' In Proceedings of the Tenth International Conference on Computational Linguistics (COLING-84). Stanford, July 2nd-6th, 1984, 461-61.

[38] Knowles, F. E. 1990. 'The Computer in Lexicography.' In F. J. Hausmann, O.

Reichmann, H. E. Wiegand, and L. Zgusta (eds.), Wörterbücher/Dictionaries/Dictionnaires, Ein internationales Handbuch zur Lexikographie/An International Encyclopedia of Lexicography/Encyclopédie internationale de lexicographie, 1. Berlin: Walter de Gruyter, 1645-72.

[39] Kussmaul, P. 1995. Training the Translator, Amsterdam/Philadelphia: John Benjamins.

[40] L'Homme, M.-C. 2008. 'Le DiCoInfo. Méthodologie pour une nouvelle génération de dictionnaires spécialisés.' Traduire 217: 78-103.

[41] Lehr, A. 1996. 'Electronic Dictionaries.' Lexicographica 12: 310-17.

[42] Mackintosh, K. 1998. 'An Empirical Study of Dictionary Use in L2-L1 Translation.' In B. T. S. Atkins (ed.), Using Dictionaries. Studies of Dictionary Use by Language Learners and Translators. Tübingen: Max Niemeyer, 123-49.

[43] Mc Creary, D. R. and R. Dolezal. 1999. 'A Study of Dictionary Use by ESL Students in an American University.' International Journal of Lexicography 12.2: 10746.

[44] Mel'čuk, I. A., A. Clas, and A. Polguère. 1995. Introduction à la lexicologie explicative et combinatoire, Brussels: Duculot.

[45] Meyer, I. 1988. 'The General Bilingual Dictionary as a Working Tool in Thème.' Meta 33.3: 368-76.

[46] Miller, G. A. 1998a. 'Foreword by George A. Miller.' In C. Fellbaum (ed.), WordNet: An Electronic Lexical Database. Cambridge (Massachusetts): MIT Press, xvxxii.

[47] Miller, G. A. 1998b. 'Nouns in WordNet.' In C. Fellbaum (ed.), WordNet: An Electronic Lexical Database. Cambridge (Massachusetts): MIT Press, 23-46.

[48] Montero, S. and P. Faber. 2008. Terminología para traductores e intérpretes, Granada: Tragacanto.

[49] Nesi, H. 1998. Dictionaries on Computer: How Different Markets Have Created Different Products. University of Warwick.

[50] Nesi, H. 1999. 'A User's Guide to Electronic Dictionaries for Language Learners.' International Journal of Lexicography 12.1: 55-66.

[51] Nesi, H. 2000a. The Use and Abuse of EFL Dictionaries. How learners of English as a Foreign Language Read and Interpret Dictionary Entries, (Lexicographica Series Maior 98). Tübingen: Max Niemeyer.

[52] Nesi, H. 2000b. 'Electronic Dictionaries in Second Language Vocabulary Comprehension and Acquisition.' In U. Heid, S. Evert, E. Lehmann, and C. Rohrer (eds.), Proceedings of the Ninth EURALEX International Congress, EURALEX 2000. Stuttgart: Institute für Maschinelle Sprachverarbeitung, Universität Stuttgart, 839-47.

[53] Nesi, H. and R. Haill. 2002. 'A Study of Dictionary Use by International Students at a British University.' International Journal of Lexicography 15.4: 277-305.

[54] Pastor, V. and A. Alcina. 2009. 'Search Techniques in Corpora for the Training of Translators.' In I. Ilisei, V. Pekar, and S. Bernardini (eds.), International Workshop on Natural Language Processing Methods and Corpora in Translation, Lexicography and Language Learning. Borovets, Bulgaria, 13-20.

[55] Pastor, V. and A. Alcina. 2010. 'Accessing Terminological Information on the 
Internet: Techniques for Translators.' In International Conference on Interdisciplinarity, Languages and ICT: Research and Teaching. University of Valencia, March 10th-12th, 2010.

[56] Pérez, C. 2002. Explotación de los córpora textuales informatizados para la creación de bases de datos terminológicas basadas en el conocimiento. $\mathrm{PhD}$ Thesis, University of Málaga. Available online at Estudios de Lingüística Española (ELiEs) $<$ http://elies.rediris.es/elies18>.

[57] Poirier, C. 1989. 'Les différents supports du dictionnaire: livre, microfiche, dictionnaire électronique.' In F. J. Hausmann, O. Reichmann, H. E. Wiegand, and L. Zgusta (eds.), Wörterbücher/Dictionaries/Dictionnaires, Ein internationales Handbuch zur Lexikographie/An International Encyclopedia of Lexicography/Encyclopédie internationale de lexicographie, 1. Berlin: Walter de Gruyter, 322-27.

[58] Rizo, A. and S. Valera. 2000. 'Lexicografía bilingüe: el español y la lengua inglesa.' In I. Ahumada (ed.), Cinco siglos de lexicografía del español. IV Seminario de Lexicografía Hispánica. Jaén, November 17th-19th, 1999. Publicaciones de la Universidad de Jaén, 341-80.

[59] Roberts, R. P. 1990. 'Translation and the Bilingual Dictionary.' Meta 35.1: 74-81.

[60] Roberts, R. P. 1997. 'Using Dictionaries Efficiently.' In M. M. Jérôme-O'Keeffe (ed.), 38th Annual Conference of the American Translators Association. San Francisco (California), 283-96.

[61] Roberts, R. P. and L. Langlois. 2001. 'L'apport de l'informatique à la recherche lexicographique.' Meta 46.4: 711-20.

[62] Robinson, D. 2003. An Introduction to the Theory and Practice of Translation, London: Routledge.

[63] Ruppenhofer, J., M. Ellsworth, M. R. L. Petruck, R. J. Christopher, and J. Scheffczyk. 2006. FrameNet II: Extended Theory and Practice. Available online at $<$ http://framenet.icsi.berkeley.edu>.

[64] Sallas, M. 2001. 'La recerca d'informació i de documentació en terminologia.' In M. T. Cabré, L. Codina, and R. Estopà (eds.), Terminologia i Documentació. Barcelona: IULA, 107-20.

[65] Sánchez, M. d. M. 2004a. 'Estudio experimental sobre el uso del diccionario como herramienta para el traductor: hacia una descripción de necesidades.' In E. Ortega (ed.), Panorama actual de la investigación en Traducción e Interpretación. Granada: Atrio, 477-86.

[66] Sánchez, M. d. M. 2004b. El uso de los diccionarios electrónicos y otros recursos de Internet como herramienta para la formación del traductor inglés-español. $\mathrm{PhD}$ Thesis, Universitat Jaume I.

[67] Santana, O., Z. Hernández, J. Pérez, G. Rodríguez, and F. Carreras. 1996. 'Diccionarios en soportes informáticos.' Cuadernos Cervantes 11: 68-77.

[68] Sharpe, P. 1995. 'Electronic Dictionaries with Particular Reference to the Design of an Electronic Bilingual Dictionary for English-speaking Learners of Japanese.' International Journal of Lexicography 8.1: 39-54.

[69] Sobkowiak, W. 1999. Pronunciation in EFL Machine-Readable Dictionaries, Poznań: Motivex.

[70] Tomaszczyk, J. 1979. 'Dictionaries: Users and Uses.' Glottodidactica 12: 103-19.

[71] Tono, Y. 1989. 'Can a Dictionary Help One Read Better?.' In G. James (ed.), Lexicographers and their Works. (Exeter Linguistic Studies 14). Exeter: University of Exeter Press, 192-200. 
[72] Varantola, K. 1998. 'Translators and their Use of Dictionaries.' In B. T. S. Atkins (ed.), Using Dictionaries. Studies of Dictionary Use by Language Learners and Translators. Tübingen: Max Niemeyer, 179-92. 


\section{Annex 1}

Table 1. Summary of the electronic dictionary analysis.

\begin{tabular}{|c|c|c|c|c|c|c|c|c|c|c|c|c|c|c|c|c|}
\hline & DUE & DRAE & OED & CED & Cercaterm & DiCoInfo & $\begin{array}{l}\text { EOHS- } \\
\text { Term }\end{array}$ & FrameNet & $\begin{array}{l}\text { Lexical } \\
\text { FreeNet }\end{array}$ & $\begin{array}{l}\text { Macmillan } \\
\text { Dictionary }\end{array}$ & $\begin{array}{l}\text { Merriam- } \\
\text { Webster }\end{array}$ & OneLook & Ultralingua & WordNet & WordReference & Wordsmyth \\
\hline $\begin{array}{l}\text { Search } \\
\text { for a word in } \\
\text { the alphabetical } \\
\text { entry list }\end{array}$ & YES & YES & YES & YES & YES & YES & YES & & & YES & YES & & & & YES & \\
\hline $\begin{array}{l}\text { Search for one } \\
\text { or more words } \\
\text { in the } \\
\text { definitions or } \\
\text { other fields of } \\
\text { an entry }\end{array}$ & YES & YES & YES & YES & & $\begin{array}{l}\text { YES } \\
\text { Option: lien } \\
\text { lexical }\end{array}$ & $\begin{array}{l}\text { YES } \\
\text { Option: } \\
\text { advanced } \\
\text { search }\end{array}$ & YES & YES & & & YES & & & $\begin{array}{l}\text { YES } \\
\text { Option: Spanish } \\
\text { definition or In } \\
\text { context (in } \\
\text { Google) }\end{array}$ & $\begin{array}{l}\text { YES } \\
\text { Option: } \\
\text { advanced } \\
\text { search }\end{array}$ \\
\hline Use of operators & $\begin{array}{l}\text { YES } \\
\&, 1, !, \text { ( ), “ } \\
\text { ". }\end{array}$ & $\begin{array}{l}\text { YES } \\
\mathrm{Y}, \mathrm{O}, \mathrm{NO} \text { in } \\
\text { búsqueda } \\
\text { múltiple }\end{array}$ & $\begin{array}{l}\text { YES } \\
\text { AND, } \\
\text { OR, NOT }\end{array}$ & $\begin{array}{l}\text { YES } \\
\text { AND, } \\
\text { OR, NOT, } \\
\text { ( ) }\end{array}$ & $\begin{array}{l}\text { YES } \\
\text { "’” }\end{array}$ & & & & & & & & & & $\begin{array}{l}\text { YES } \\
+,-, \text {, ” }\end{array}$ & $\begin{array}{l}\text { YES } \\
\text { Options: All } \\
\text { of the words, } \\
\text { any of the } \\
\text { words in } \\
\text { advanced } \\
\text { search }\end{array}$ \\
\hline $\begin{array}{l}\text { Search for a } \\
\text { semantic } \\
\text { relation by } \\
\text { navigation } \\
\end{array}$ & YES & YES & YES & YES & YES & YES & YES & YES & YES & YES & YES & YES & YES & YES & YES & YES \\
\hline $\begin{array}{l}\text { Search for a } \\
\text { semantic } \\
\text { relation by } \\
\text { direct search }\end{array}$ & & & & & & $\begin{array}{l}\text { YES } \\
\text { Option: lien } \\
\text { lexical }\end{array}$ & $\begin{array}{l}\text { YES } \\
\text { Field related } \\
\text { terms }\end{array}$ & & $\begin{array}{l}\text { YES } \\
\text { Options: } \\
\text { show } \\
\text { related } \\
\text { and show } \\
\text { reachable } \\
\end{array}$ & $\begin{array}{l}\text { YES } \\
\text { Thesaurus }\end{array}$ & $\begin{array}{l}\text { YES } \\
\text { Thesaurus }\end{array}$ & $\begin{array}{l}\text { YES } \\
\text { Direct } \\
\text { search with } \\
\text { keywords }\end{array}$ & $\begin{array}{l}\text { YES } \\
\text { English } \\
\text { synonym } \\
\text { dictionary }\end{array}$ & YES & $\begin{array}{l}\text { YES } \\
\text { Spanish synonym } \\
\text { dictionary }\end{array}$ & $\begin{array}{l}\text { YES } \\
\text { Options: } \\
\text { synonyms, all } \\
\text { word relations }\end{array}$ \\
\hline $\begin{array}{l}\text { Access to } \\
\text { complementary } \\
\text { forums }\end{array}$ & & & & & & & & & & & & & & & YES & \\
\hline Search & & & & & YES & & YES & YES & & & YES & & & & & \\
\hline
\end{tabular}




\begin{tabular}{|c|c|c|c|c|c|c|c|c|c|c|c|c|c|c|c|c|}
\hline by thematic area & & & & & $\begin{array}{l}\text { Restrict } \\
\text { subject area }\end{array}$ & & $\begin{array}{l}\text { Option: full } \\
\text { list by } \\
\text { domain }\end{array}$ & $\begin{array}{l}\text { Search by } \\
\text { frame }\end{array}$ & & & $\begin{array}{l}\text { Navigating } \\
\text { or direct } \\
\text { search with } \\
\text { keywords }\end{array}$ & & & & & \\
\hline $\begin{array}{l}\text { Access to } \\
\text { external links }\end{array}$ & & & & & & $\begin{array}{l}\text { YES } \\
\text { It has no } \\
\text { links but } \\
\text { includes } \\
\text { context } \\
\text { fields with } \\
\text { contexts } \\
\text { extracted } \\
\text { from a } \\
\text { corpus } \\
\end{array}$ & $\begin{array}{l}\text { YES } \\
\text { Links to } \\
\text { concordances } \\
\text { of a corpus }\end{array}$ & $\begin{array}{l}\text { YES } \\
\text { It has no } \\
\text { links but } \\
\text { includes } \\
\text { contexts } \\
\text { extracted } \\
\text { from a } \\
\text { corpus }\end{array}$ & & & & $\begin{array}{l}\text { YES } \\
\text { Links to } \\
\text { other } \\
\text { dictionaries }\end{array}$ & & & $\begin{array}{l}\text { YES } \\
\text { Link to Google }\end{array}$ & \\
\hline $\begin{array}{l}\text { Search for } \\
\text { images }\end{array}$ & & & & & & & & & & & $\begin{array}{l}\text { YES } \\
\text { In the } \\
\text { visual } \\
\text { dictionary } \\
\text { with a } \\
\text { thematic } \\
\text { index or } \\
\text { direct } \\
\text { search with } \\
\text { keywords } \\
\end{array}$ & & & & $\begin{array}{l}\text { YES } \\
\text { In Google }\end{array}$ & \\
\hline $\begin{array}{l}\text { Introduction of } \\
\text { an exact word }\end{array}$ & YES & YES & YES & YES & YES & YES & YES & YES & YES & YES & YES & YES & YES & YES & YES & YES \\
\hline $\begin{array}{l}\text { Introduction of } \\
\text { a partial word }\end{array}$ & $\begin{array}{l}\text { YES } \\
\text { With } \\
\text { wildcards }\end{array}$ & $\begin{array}{l}\text { YES } \\
\text { Introduction } \\
\text { of the } \\
\text { beginning } \\
\text { of a word } \\
\text { and indice } \\
\text { de todss las } \\
\text { palabras } \\
\text { option, or } \\
\text { introduction } \\
\text { of the end } \\
\text { of a word } \\
\text { and } \\
\text { busqueda } \\
\text { inversa } \\
\text { option }\end{array}$ & $\begin{array}{l}\text { YES } \\
\text { With } \\
\text { wildcards }\end{array}$ & $\begin{array}{l}\text { YES } \\
\text { With } \\
\text { wildcards }\end{array}$ & $\begin{array}{l}\text { YES } \\
\text { With } \\
\text { wildcards }\end{array}$ & $\begin{array}{l}\text { YES } \\
\text { Options: } \\
\text { Terme } \\
\text { commencant } \\
\text { par and } \\
\text { Terme } \\
\text { contenant }\end{array}$ & $\begin{array}{l}\text { YES } \\
\text { Introducing a } \\
\text { sequence of } \\
\text { characters } \\
\text { without } \\
\text { wildcards }\end{array}$ & & $\begin{array}{l}\text { YES } \\
\text { Option: } \\
\text { substring }\end{array}$ & $\begin{array}{l}\text { YES } \\
\text { Auto- } \\
\text { complete } \\
\text { feature }\end{array}$ & & $\begin{array}{l}\text { YES } \\
\text { With } \\
\text { wildcards }\end{array}$ & $\begin{array}{l}\text { YES } \\
\text { Option: word } \\
\text { hunt }\end{array}$ & & $\begin{array}{l}\text { YES } \\
\text { Auto-complete } \\
\text { feature }\end{array}$ & $\begin{array}{l}\text { YES } \\
\text { With } \\
\text { wildcards }\end{array}$ \\
\hline $\begin{array}{l}\text { Use of } \\
\text { wildcards }\end{array}$ & $\begin{array}{l}\text { YES } \\
* ?\end{array}$ & $\begin{array}{l}\text { YES } \\
*, ?,+,[\ldots],\end{array}$ & $\begin{array}{l}\text { YES } \\
* ?\end{array}$ & $\begin{array}{l}\text { YES } \\
* ?\end{array}$ & $\begin{array}{l}\text { YES } \\
*, ?\end{array}$ & & & & & & & $\begin{array}{l}\text { YES } \\
* ?\end{array}$ & $\begin{array}{l}\text { YES } \\
*, ?,+\end{array}$ & & & $\begin{array}{l}\text { YES } \\
*, \%, . .\end{array}$ \\
\hline
\end{tabular}




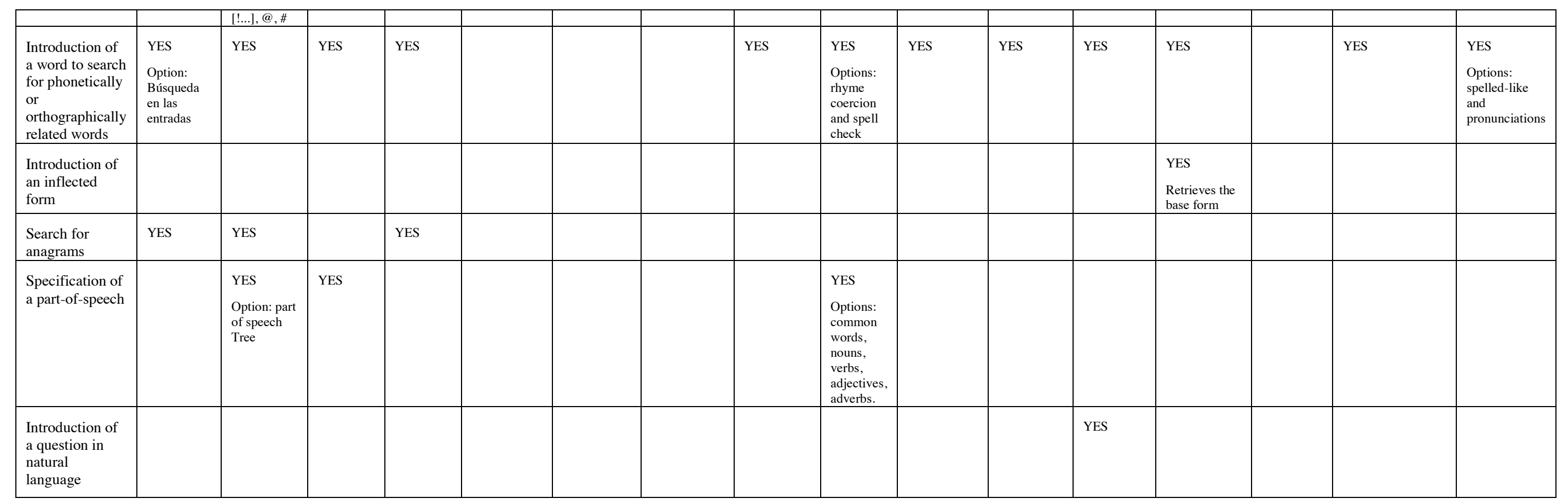

